\title{
The Macrophage Galactose-Type Lectin-1 (MGL1) Recognizes Taenia crassiceps Antigens, Triggers Intracellular Signaling, and Is Critical for Resistance to This Infection
}

\author{
Daniel Montero-Barrera, ${ }^{1}$ Héctor Valderrama-Carvajal, ${ }^{1}$ César A. Terrazas, ${ }^{2}$ \\ Saúl Rojas-Hernández, ${ }^{3}$ Yadira Ledesma-Soto, ${ }^{1}$ Laura Vera-Arias, ${ }^{1}$ \\ Maricela Carrasco-Yépez, ${ }^{4}$ Lorena Gómez-García, ${ }^{5}$ Diana Martínez-Saucedo, ${ }^{1}$ \\ Mireya Becerra-Díaz, ${ }^{1}$ and Luis I. Terrazas ${ }^{1}$ \\ ${ }^{1}$ Unidad de Biomedicina, Facultad de Estudios Superiores-Iztacala, Universidad Nacional Autónoma de México (UNAM), \\ Avenue de los Barrios 1, Los Reyes Iztacala, 54090 Tlalnepantla, MEX, Mexico \\ ${ }^{2}$ Department of Pathology, The Ohio State University Medical Center, Columbus, OH, USA \\ ${ }^{3}$ Sección de Estudios de Postgrado e Investigación, Escuela Superior de Medicina, Instituto Politécnico Nacional, Mexico \\ ${ }^{4}$ Proyecto CyMA, UIICSE, FES Iztacala, UNAM, 54090 Tlalnepantla, MEX, Mexico \\ ${ }^{5}$ Instituto Nacional de Cardiología "Ignacio Chávez," 14080 Mexico, DF, Mexico \\ Correspondence should be addressed to Luis I. Terrazas; literrazas@campus.iztacala.unam.mx
}

Received 9 August 2014; Revised 14 October 2014; Accepted 15 October 2014

Academic Editor: Abraham Landa

Copyright (C) 2015 Daniel Montero-Barrera et al. This is an open access article distributed under the Creative Commons Attribution License, which permits unrestricted use, distribution, and reproduction in any medium, provided the original work is properly cited.

C-type lectins are multifunctional sugar-binding molecules expressed on dendritic cells (DCs) and macrophages that internalize antigens for processing and presentation. Macrophage galactose-type lectin 1 (MGL1) recognizes glycoconjugates expressing Lewis $\mathrm{X}$ structures which contain galactose residues, and it is selectively expressed on immature DCs and macrophages. Helminth parasites contain large amounts of glycosylated components, which play a role in the immune regulation induced by such infections. Macrophages from $\mathrm{MGL1}^{-1-}$ mice showed less binding ability toward parasite antigens than their wild-type (WT) counterparts. Exposure of WT macrophages to T. crassiceps antigens triggered tyrosine phosphorylation signaling activity, which was diminished in $\mathrm{MGL1}^{-1-}$ macrophages. Following T. crassiceps infection, $\mathrm{MGL1}^{-1-}$ mice failed to produce significant levels of inflammatory cytokines early in the infection compared to WT mice. In contrast, $\mathrm{MGL1}^{-1-}$ mice developed a Th2-dominant immune response that was associated with significantly higher parasite loads, whereas WT mice were resistant. Flow cytometry and RT-PCR analyses

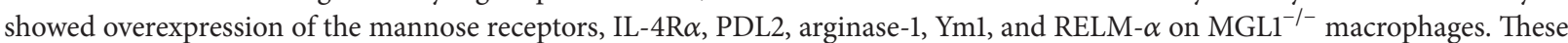
studies indicate that MGL1 is involved in T. crassiceps recognition and subsequent innate immune activation and resistance.

\section{Introduction}

Pattern recognition receptors (PRRs) function to rapidly detect pathogen invasion as well as to control innate immune activation leading to inflammation. The PRRs of dendritic cells (DCs) and macrophages (M $\phi \mathrm{s})$, among others, recognize and bind to conserved pathogen motifs such as LPS in gramnegative bacteria, flagellin, viral RNA, and several molecules in intracellular protozoa [1], including cyclophilin from Toxoplasma gondii [2] and GIPL from Trypanosoma cruzi [3].
Among the PRRs, the Toll-like receptor (TLR) family is the main group of receptors known to be involved in maturation and inducing inflammatory cytokines in DCs and $\mathrm{M} \phi \mathrm{s}$ [1]. Other types of PRRs are the C-type lectin receptors (CLRs), which have selective affinity for a carbohydrate or group of carbohydrates in a $\mathrm{Ca}^{2+}$-dependent manner; CLRs also play a role in recognizing different pathogens, including bacteria, fungal, and viral glycoconjugates [4-7]. However, there is a less-defined function for CLRs in response to helminth infections. 
It has been largely demonstrated that helminths display a variety of glycan moieties on their antigens, which may participate in the induction of Th2 responses $[8,9]$ and in immune downregulation, both characteristics of helminth infections [10]. Nevertheless, given the complexity of these molecules, it may also be expected that some helminth glycoconjugates display immunostimulatory activities [11].

Some helminth parasites have been reported to be recognized by different CLRs, for example, dendritic cell-specific ICAM-3 grabbing integrin (DC-SIGN), mannose receptor (MR), macrophage galactose-type lectin (MGL), and SIGNrelated 1 (SIGNR1) bind different glycans on soluble egg antigens from Schistosoma mansoni in vitro $[12,13]$. Trichuris muris, a nematode, is also recognized by the MR, but such CLRs appear to play a limited role in protection or susceptibility in both parasitic infections given that mice lacking the MR or SIGNR1 mount a normal immune response and clear these infections as usual [14].

Taenia crassiceps is a cestode that is useful for understanding the host-parasite relationship in cysticercosis. Glycoconjugates of T. crassiceps and other cestodes have been shown to induce strong Th2-biased responses in vivo [15] and to modulate both human and mouse DC activity in vitro [16-18]. We have previously reported that most of the T. crassiceps antigens bind to concanavalin A, indicating that they are glycosylated with glucose, mannose, or galactose $[15,17,19]$. The natural candidates for such carbohydrate recognition are CLRs, such as the MR, MGL, and DC-SIGN. As mentioned before, DC-SIGN and the MR have been shown to be irrelevant for Schistosoma or Trichuris protection. We therefore focused our study on MGL1. MGL1 is mainly found on $\mathrm{M} \phi$ s and immature DCs, although it was recently reported to be expressed on mast cells [4], and it recognizes glycoconjugates expressing galactose and $\mathrm{N}$-acetyl-galactosamine residues. Because the ability of MGL1 to act as an autonomous receptor has been appreciated only recently, the molecular regulation of its signaling pathway is partly known [20], but its biological role in response to helminth infections is still unrevealed. Recently, it has been shown that upon strong MGL engagement with polyclonal anti-MGL antibodies, this receptor is able to signal through tyrosine phosphorylation and induce ERK signaling [20], however, whether MGL signals after a "natural" ligation is also unknown.

To clarify the role of MGL1 in the recognition and defense against a helminth infection, we infected wild-type and MGL1-deficient mice (MGL1 ${ }^{-/-}$) with Taenia crassiceps. Our data demonstrated that MGL1-deficient mice exhibited reduced parasite clearance, despite strong induction of Th2 responses. $\mathrm{MGL1}^{-/-}$macrophages displayed reduced intracellular signaling in response to Taenia antigens and lower TNF$\alpha$ and NO production. Taken together, our data suggest that MGL1 plays a key role in driving macrophage responses in vivo and thus may act as an important mediator of resistance to this helminth infection.

\section{Materials and Methods}

2.1. Mice. Six- to eight-week-old female $\mathrm{MGL1}^{-/-}$mice on a C57BL/6 background were donated by Glycomics Consortium (USA). $\mathrm{MGL1}^{-/-}$mice have been backcrossed for more than 7 generations on a C57BL/6NHsd genetic background with mice from Harlan Laboratories (México). In some experiments BALB/c mice were purchased from Harlan Laboratories (México). All mice were maintained in a pathogenfree environment at the FES-Iztacala, UNAM animal facilities, according to the Faculty Animal Care and Use Committee and government guidelines (official Mexican regulation NOM-062-ZOO-1999), which are in strict accordance with the recommendations in the Guide for the Care and Use of Laboratory Animals of the National Institutes of Health, USA.

2.2. Parasites and Infection. Metacestodes of $T$. crassiceps were harvested from the peritoneal cavity of female BALB/c mice after 2 to 3 months of infection. The cysticerci were washed four times in sterile phosphate-buffered saline (PBS) (0.15 M, pH 7.2). Experimental infection was achieved by intraperitoneal (i.p.) injection with 20 small (approx. $2 \mathrm{~mm}$ in diameter) nonbudding cysticerci of $T$. crassiceps suspended in $0.3 \mathrm{~mL}$ of PBS per mouse.

2.3. Lectin-Blot Analysis on T. crassiceps Soluble Antigens. T. crassiceps was lysed by sonication with one 10 -s pulse at $100 \mathrm{~W}$ of amplitude (Fisher Sonic Dismembrator model 300). The resulting suspension was centrifuged at $4^{\circ} \mathrm{C}$ for $1 \mathrm{~h}$ at $2700 \mathrm{~g}$, and the pellet was discarded and we keep the supernatant. Soluble antigen was concentrated and quantified by the Bradford method. A total of $20 \mu \mathrm{g}$ of protein of T. crassiceps soluble antigens (TcSol) was separated by SDS-PAGE (10\%) and electroblotted (400 $\mathrm{mA}$ for $1 \mathrm{~h})$ onto a nitrocellulose membrane [21].

For the detection of carbohydrates with residues of galactose or $N$-acetylgalactosamine, strips of nitrocellulose were blocked with $1 \%$ BSA diluted in PBS-T (10 mM sodium phosphate buffer, $150 \mathrm{mM} \mathrm{NaCl}$ and $0.5 \%$ Tween 20) and incubated overnight at $4^{\circ} \mathrm{C}$. The membranes were treated with a biotinylated lectin (Hp or RCA) at a concentration of $5 \mu \mathrm{g} / \mathrm{mL}$ diluted 1:500 in PBS-T and incubated overnight at $4^{\circ} \mathrm{C}$ (Sigma-Aldrich, St. Louis, MO, USA). The next day, the membranes were incubated with SBHP, the strips were washed with PBS, and enzyme activities were then detected by a substrate solution $\left(0.1 \% \mathrm{H}_{2} \mathrm{O}_{2}, 17.5 \%\right.$ methanol, $0.15 \% 4-$ chloro- $\alpha$-naphthol and $82.5 \%$ PBS) following a $15-\mathrm{min}$ incubation. The proteins that reacted with the lectins were identified on the nitrocellulose strips.

2.4. FITC Labeling of T. crassiceps Antigens. T. crassiceps soluble products (TcSol) were labeled with FITC (Sigma) according to the manufacturer's instructions. Briefly, $1 \mathrm{mg} / \mathrm{mL}$ TcSol was prepared in $0.1 \mathrm{M}$ sodium bicarbonate buffer, $\mathrm{pH}$ 9. FITC was dissolved in DMSO at $1 \mathrm{mg} / \mathrm{mL}$, and $500 \mu \mathrm{L}$ of the FITC solution was slowly added to TcSol in $5 \mu \mathrm{L}$ aliquots while gently stirring. The TcSol-FITC solution was incubated for $8 \mathrm{~h}$ at $4^{\circ} \mathrm{C}$ in the dark and washed 3 times with PBS; protein was quantified by the Bradford assay and maintained at $4^{\circ} \mathrm{C}$.

2.5. Cell Preparations and Culture Conditions. The spleen was removed from infected mice under sterile conditions. Singlecell suspensions were prepared by gently teasing apart the 
spleen in RPMI-1640 supplemented with $10 \%$ fetal bovine serum, 100 units of penicillin/streptomycin, $2 \mathrm{mM}$ glutamine, $25 \mathrm{mM}$ HEPES buffer and 1\% nonessential amino acids (all from GIBCO, BRL Grand Island, New York). The cells were centrifuged, and the erythrocytes were lysed by resuspending the cells in Boyle's solution (0.17 M Tris and 0.16 M ammonium chloride). Following two washes, the viable cells were counted by trypan blue exclusion with a Neubauer hemocytometer, and the splenocytes were adjusted to $3 \times 10^{6}$ cells $/ \mathrm{mL}$ in the same medium. Aliquots $(100 \mu \mathrm{L})$ of the adjusted cell suspensions were placed into 96-well flat bottom culture plates (Costar, Cambridge, Massachusetts) and stimulated with a soluble extract of T. crassiceps $(25 \mu \mathrm{g} / \mathrm{mL})$ or with platebound anti-CD3 antibody $(1 \mu \mathrm{g} / \mathrm{mL})$ at $37^{\circ} \mathrm{C}$ for $72 \mathrm{~h}$. The supernatants from these cultures were analyzed for IL-4 and IFN- $\gamma$ (PeproTech, México) production by ELISA.

2.6. Cytokine and Nitric Oxide Production by Peritoneal Macrophages. Peritoneal exudate cells (PECs) were obtained from uninfected thioglycolate-injected mice and from mice following 2, 4, and 8 weeks of T. crassiceps infection. PECs were adjusted to $5 \times 10^{6} / \mathrm{mL}$ in supplemented RPMI and plated in 6-well plates (Costar). After 2 hours at $37^{\circ} \mathrm{C}$ and $5 \%$ $\mathrm{CO}_{2}$, nonadherent cells were removed and adherent cells were gently scrapped using cold PBS and readjusted to $1 \times$ $10^{6} / \mathrm{mL}$. Viability at this point was $>90 \%$. These cells were $>90 \%$ macrophages according to FACS analysis $\left(\mathrm{F} 4 / 80^{+}\right.$, BioLegend, San Diego, CA). Then, $1 \mathrm{~mL}$ of the cell suspension was plated, and cells were activated in 24-well plates (Costar) with LPS (1 $\mu \mathrm{g} / \mathrm{mL}$, E. coli 111:B4; Sigma, St Louis, MO.), followed by incubation for $24 \mathrm{~h}$. TNF- $\alpha$, IL-12 (PeproTech) and nitric oxide (Griess reaction) were examined in supernatants.

\subsection{Generation of Bone Marrow Derived M $\phi s$ (BMDM $\phi s)$.} $\mathrm{BMDM} \phi$ s from WT or $\mathrm{MGL1}^{-/-}$mice were obtained as previously described [22]. Briefly, bone marrow cells were isolated by flushing femurs and tibias with culture media. Bone marrow cells were plated at $1 \times 10^{6}$ cells $/ \mathrm{mL}$ in medium supplemented RPMI medium supplemented with 10\% SFB and penicillin/streptomycin plus $20 \mathrm{ng} / \mathrm{mL}$ murine recombinant macrophage colony-stimulating factor (M-CSF, Peprotech Mexico). On day 3, fresh media containing M-CSF was added. On day 7 , nonadherent cells were removed, and adherent cells were detached and centrifuged at $1500 \mathrm{rpm}$ at $4^{\circ} \mathrm{C}$ for $15 \mathrm{~min}$. Adherent cells $\left(\mathrm{F} 4 / 80^{+}\right)$were resuspended in fresh media and cultured for an additional $24 \mathrm{~h}$ in 12 -well plates.

2.8. In Vitro Stimulation of BMDM $\phi$ s and Protein Extraction. Bone marrow cells were differentiated as described above. On day 7 , the $\mathrm{M} \phi$ s were harvested and plated at $2.5 \times 10^{6}$ cells/mL in six-well plates. The cells were used 24 hours after plating to eliminate any residual effects from M-CSF. M $\phi$ s were stimulated with the TcSol $(50 \mu \mathrm{g} / \mathrm{mL})$ for 5,15 , or $30 \mathrm{~min}$. After stimulation, the cells were centrifuged at $1500 \mathrm{rpm}$ for 5 min and washed with PBS. The cells were then lysed with lysis buffer for $15 \mathrm{~min}$, and the lysates were quantified using the BCA assay (Thermo Scientific) and then frozen at $-80^{\circ} \mathrm{C}$ until further use.
2.9. Western Blot Assays. Whole-cell lysates were resolved by SDS-PAGE ( $40 \mu \mathrm{g}$ of protein was loaded into each well) using $10 \%$ acrylamide mini-gels, followed by electrophoretic transfer to PVDF membranes (Immobilon-P MILLIPORE) for $2 \mathrm{~h}$. Membranes were blocked with 5\% fat-free milk in PBS for $2 \mathrm{~h}$ and incubated with primary antibodies overnight. The detection step was performed with peroxidase-coupled antimouse IgG and anti-rabbit IgG (BioLegend, 1:2000) and anti-goat IgG (Santa Cruz Biotechnology) for $2 \mathrm{~h}$. The primary antibodies included antiphosphotyrosine (Santa Cruz Biotechnology) and $\beta$-Actin (BioLegend). All primary antibodies were diluted 1:500 in 1\% fat-free milk in PBS. Blots were developed with the ECL detection system according to the manufacturer's instructions (Amersham). Blots are representative of two separate experiments.

2.10. Detection of Nitric Oxide Production. Nitric oxide production by macrophages was assayed by determining the increase in nitrite concentration [23] by the Griess reaction adapted to microwell plates (Costar). Briefly, $50 \mu \mathrm{L}$ of culture supernatant was mixed with an equal volume of Griess reagent and incubated for $10 \mathrm{~min}$ at room temperature in the dark; the absorbance was measured at $570 \mathrm{~nm}$ in an automatic microplate reader (Organon Technika Microwell System). Values were quantified using serial dilutions of sodium nitrite.

2.11. Flow Cytometry Analysis. Peritoneal exudate cells (PECs) were obtained from naïve or infected mice by injecting $10 \mathrm{~mL}$ of ice-cold PBS. For flow cytometry, single cell suspensions of the PECs obtained during the sacrifice were stained with anti-F4/80, anti-PDL2, anti-IL-4R $\alpha$, anti-MGL1, and anti-MGL2 antibodies (Biolegend, San Diego, CA), for $30 \mathrm{~min}$ at $4^{\circ} \mathrm{C}$. The cells were washed twice and analyzed using the FACSCalibur system and Cell Quest software (Becton Dickinson, USA).

2.12. Reverse Transcription (RT)-PCR Analyses. The levels of arginase 1 (Arg-1), Ym-1 and resistin-like molecule- $\alpha$ (RELM$\alpha)$ mRNA transcripts in adherent peritoneal macrophages (which were allowed to adhere for $2 \mathrm{~h}$ at $37^{\circ} \mathrm{C}$ and $5 \% \mathrm{CO}_{2}$ ) were determined using RT-PCR. At the indicated time points, adherent peritoneal macrophages from T. crassiceps-infected $\mathrm{MGL1}^{+/+}$and MGL1 ${ }^{-/-}$mice were aseptically removed and without any further stimulation (basal) or LPS + IFN- $\gamma$ stimulation $(1 \mu \mathrm{g}$ and $20 \mathrm{ng} / \mathrm{mL}$, resp.) were processed for RNA extraction using TRIzol reagent (Invitrogen, Carlsbad, CA, USA) and the propanol-chloroform technique. The RNA was quantified, and $3 \mu \mathrm{g}$ of RNA was reverse transcribed using the Superscript II First Strand Synthesis Kit (Invitrogen) and an oligo dT primer, as recommended by the manufacturer. Once cDNA was obtained, conventional PCR was performed. The PCR reactions contained (in a $25 \mu \mathrm{L}$ final volume) 5X PCR Buffer blue, $10 \mathrm{mM}$ dNTP, $40 \mathrm{nM}$ each of the forward and reverse primers (Table 1), $1 \mathrm{U}$ Taq DNA polymerase (Sacace Biotechnologies, Italy) and $2 \mu \mathrm{L}$ of the cDNA. The program used for the amplification of each gene contained an initial denaturation step at $95^{\circ} \mathrm{C}$ for $5 \mathrm{~min} ; 35$ 
TABLE 1: The following primer pairs were used in this study.

\begin{tabular}{|c|c|c|c|}
\hline Gen & Sequence & Melting temperature & Number of cycles \\
\hline GAPDH & $\begin{array}{l}\text { Forward -CTCATGACCACAGTCCATGC- } \\
\text { Reverse -CACATTGGGGGTAGGAACAC- }\end{array}$ & $54^{\circ} \mathrm{C}$ & 35 \\
\hline Arg-1 & $\begin{array}{l}\text { Forward -CAGAAGAATGGAAGAGTCAG- } \\
\text { Reverse -CAGATATGCAGGGAGTCACC- }\end{array}$ & $54^{\circ} \mathrm{C}$ & 35 \\
\hline Ym-1 & $\begin{array}{l}\text { Forward -TCACAGGTCTGGCAATTCTTCTG- } \\
\text { Reverse -TTTGTCCTTAGGAGGGCTTCCTC- }\end{array}$ & $56^{\circ} \mathrm{C}$ & 35 \\
\hline Fizz-1 & $\begin{array}{l}\text { Forward -GGTCCCAGTGCATATGGATGAGACCATAG- } \\
\text { Reverse -CACCTCTTCACTCGAGGGACAGTTGGCAGC- }\end{array}$ & $65^{\circ} \mathrm{C}$ & 35 \\
\hline iNOS & $\begin{array}{l}\text { Forward -GCCACCAACAATGGCAACAT- } \\
\text { Reverse -AAGACCAGAGGCAGCACATC- }\end{array}$ & $60^{\circ} \mathrm{C}$ & 30 \\
\hline
\end{tabular}

cycles of $95^{\circ} \mathrm{C}$ for $40 \mathrm{~s}$, the indicated melting temperature for $50 \mathrm{~s}$ and $72^{\circ} \mathrm{C}$ for $40 \mathrm{~s}$; and a final extension step at $72^{\circ} \mathrm{C}$ for $4 \mathrm{~min}$. All reactions were performed in a thermal cycler (Corbett Research, Australia). Finally, to observe the amplified products, a 1.5\% agarose gel was prepared, and samples were loaded with blue juice buffer containing SYBR Green (Invitrogen). The gels were visualized using a Fujifilm FLA 5000 scanner (Fuji, Japan) with FLA 5000 image reader V2.1 software to capture the images. The specificity of the PCR was verified by the absence of signal in the no-template controls of macrophage samples. The sequences of the primers used have been previously reported [24].

2.13. Antibody ELISAs. Peripheral blood was collected at 2wk intervals from tails snips of the T. crassiceps-infected $\mathrm{MGL1}^{+/+}$and $\mathrm{MGL1}^{-/-}$mice. T. crassiceps-specific IgG1 and IgG2a levels were determined by ELISA as previously described. The results are expressed as the maximal serum dilution (endpoint titer) at which Optical Density was detected (OD). Total IgE production was detected by Opt-ELISA from Biolegend.

2.14. Statistical Analysis. Comparisons between the wild-type and $\mathrm{MGL1}^{-/-}$groups in this study were performed using Student's unpaired $t$ test. $P<0.05$ was considered significant. The statistical significance of the serum titers was determined by nonparametric tests using the Mann-Whitney U/Wilcoxon Rank tests.

\section{Results}

3.1. Taenia crassiceps Soluble Antigens Express Glycoconjugates Containing N-Acetylgalactosamine and Galactose Residues. To detect the expression of glycoconjugates on soluble antigens of T. crassiceps, a lectin-blot assay was performed using Helix pomatia (specific for $\mathrm{N}$-acetylgalactosamine residues) and Ricinus comunis (specific for galactose residues) lectins. Several glycoconjugates were recognized by both lectins, those of 310, 287, 250, 210, 182, 161, 79, 77, 75, 49, 47, and $41 \mathrm{kDa}$ (Figure 1(a)), whereas two bands at 51 and $39 \mathrm{KDa}$ were only recognized by $H$. pomatia. However, using only streptavidin peroxidase (Figure 1(b)), two glycoconjugates were recognized on TcSol antigens, those of 250 and $124 \mathrm{kDa}$. Therefore,

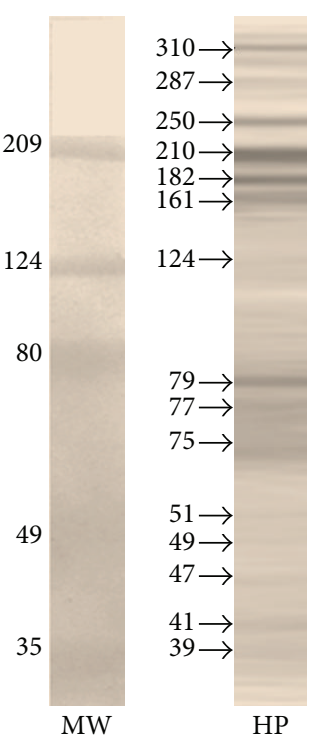

(a)

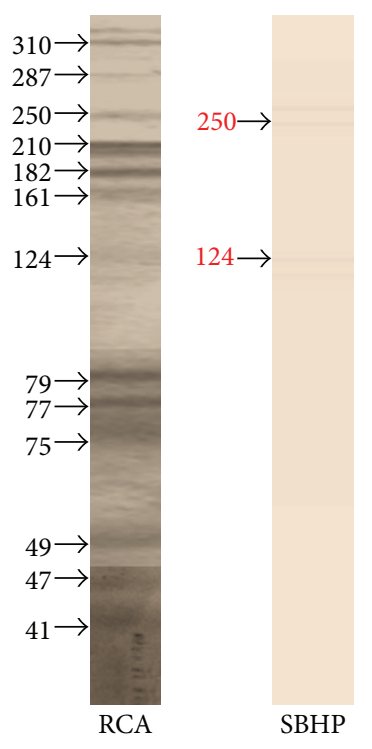

(b)
Figure 1: Lectin-blot analysis of Taenia crassiceps soluble antigens. T. crassiceps soluble proteins were subjected to electrophoresis on a $10 \%$ SDS-polyacrylamide gel, transferred to nitrocellulose membrane, and revealed with a couple of different biotinylated lectins. (a) MW-molecular weight, HP-Helix pomatia and RCARicinus communis. (b) The strips were incubated only with SBHPstreptavidin-bound horseradish peroxidase.

the presence of these two biotin-containing proteins most likely corresponds to biotin-dependent carboxylases recognized by streptavidin alone $[25,26]$. These findings indicate that TcSol antigens express high levels of glycoconjugates with $\mathrm{N}$-acetylgalactosamine and galactose residues.

\section{2. $\mathrm{MGL1}^{-1-}$ Macrophages Display Reduced Binding to Tae-} nia crassiceps Soluble Antigens. The innate recognition of pathogen-associated molecules by antigen-presenting cells is crucial to the initiation of the immune response. Different studies have shown that helminth-derived molecules can be recognized by C-type lectins [27, 28]. In our model, we previously reported that most TcSol bound to concanavalin 
A, indicating that TcSol are glycosylated with glucose, mannose or galactose [17], whereas Jang Lee et al. reported that the main $\mathrm{N}$-glycan structures in $T$. crassiceps were mannose, fucose, galactose and GlcNAc. They also found a rare Fuc $\alpha 1$ $\rightarrow$ 3GlcNAc antenna on T. crassiceps molecules [29]. Thus, the natural candidates for carbohydrate recognition on $T$. crassiceps are CLRs, such as the MR, MGL, and DC-SIGN. Thus, we hypothesized that one of the possible receptors that bind the glycomolecules on TcSol may be MGL, given its specificity to recognize both $\mathrm{N}$-acetylgalactosamine and galactose residues. To investigate the role of MGL1 in TcSol recognition, TcSol antigens were labeled with FITC to perform binding assays. TcSol-FITC efficiently bound to $\mathrm{MGL1}^{+/+}$macrophages at $37^{\circ} \mathrm{C}$ (approximately $30 \%$ of cells were positive), indicating that TcSol-FITC can be recognized and internalized by these cells (Figures 2(a) and 2(b)). Incubation of $\mathrm{M} \phi$ s and $\mathrm{TcSol}$ at $4^{\circ} \mathrm{C}$ showed reduced fluorescence (5-10\%) indicating a low level of binding. Next, we similarly exposed $\mathrm{MGL1}^{-/-} \mathrm{M} \phi$ s to TcSol-FITC at $37^{\circ} \mathrm{C}$ and found significant reductions in both the percentage of TcSol-FITCpositive cells (approximately 10\%) and the mean fluorescence intensity (MFI) of TcSol-FITC on these cells (Figure 2(c)). These data suggest that $\mathrm{M} \phi$ s can recognize TcSol via MGL.

3.3. The Absence of MGL1 on Macrophages Impairs TcSolTriggered Global Tyrosine Phosphorylation. The fact that TcSol binding was impaired in $\mathrm{MGL1}^{-/-} \mathrm{M} \phi \mathrm{s}$, led us to question whether the interaction with MGL-TcSol triggers an intracellular signaling pathway. Recent advances in the understanding of the intracellular signaling induced by strong antibody-mediated crosslinking of MGL have highlighted a possible role for the ERK pathway [20]. To determine whether TcSol can induce intracellular signaling, we exposed BMDM $\phi$ s from $\mathrm{MGLl}^{+/+}$or $\mathrm{MGL1}^{-/-}$mice to TcSol for 5, 15, and $30 \mathrm{~min}$ and found that tyrosine phosphorylation was enhanced in $\mathrm{MGL1}^{+/+}$macrophages; interestingly, tyrosine phosphorylation was detected as early as $5 \mathrm{~min}$ and remained for at least $30 \mathrm{~min}$ (Figure 3(a)). In contrast, $\mathrm{MGL1}^{-/-} \mathrm{BMDM} \phi$ s that were similarly exposed to TcSol displayed a lower and less-sustained tyrosine phosphorylation in several protein bands (Figure 3(a), arrows). To further analyze this response we stimulated both $\mathrm{MGL1}^{+/+}$and $\mathrm{MGL1}^{-/-}$ $\mathrm{BMDM} \phi$ s with LPS $(500 \mathrm{ng} / \mathrm{mL}$ ) or TcSol again for $30 \mathrm{~min}$. As observed in Figure 3(b), also we detected a lack of response to LPS and a lower tyrosine phosphorylation in response to TcSol (Figures 3(b) and 3(c), resp.) in $\mathrm{MGL1}^{-/-} \mathrm{BMDM} \phi$ s.

3.4. Mice Lacking MGL1 Are Highly Susceptible to Taenia crassiceps Infection. After determining that T. crassiceps antigens can be recognized by MGL1 and that macrophages deficient in MGL1 are partially refractory to TcSol stimulation, we investigated the in vivo role of this molecule in experimental cysticercosis using MGL-deficient mice. To approach this question, we compared the course of T. crassiceps infection in $\mathrm{MGL1}^{-/-}$with that in $\mathrm{MGL1}^{+/+}$mice. As a control for susceptibility, we used $\mathrm{BALB} / \mathrm{c}$ mice, which have consistently been reported as a highly susceptible strain to $T$. crassiceps infection [30].

We examined the kinetics of parasite growth from 2 to 8 weeks after T. crassiceps infection. Early in the infection (2 weeks) both groups of mice displayed comparable parasite burdens (Figure 4(a)). Interestingly, as infection progressed, by the fourth week of infection, the number of larvae in the peritoneal cavity increased significantly in $\mathrm{MGL1}^{-/-}$mice compared to $\mathrm{MGL1}^{+/+}$mice, which successfully reduced the number of parasites by week 8 after infection (Figures 4(a) and 4(b)). In fact, $\mathrm{MGL1}^{-/-}$mice exhibited a parasite burden that was very similar to that in the susceptible strain of mice $(\mathrm{BALB} / \mathrm{c})$, which were consistently observed as very susceptible to T. crassiceps infection (Figure 4(a)). These findings suggest that the MGL1-mediated signaling pathway is involved in resistance during $T$. crassiceps infection on a resistant genetic background such as C57BL/6.

\section{5. $\mathrm{MGLI}^{-1-}$ Mice Display an Altered Immune Response} to Taenia crassiceps. A few studies have demonstrated that MGL can mediate signaling after a strong stimulus such as polyclonal anti-MGL antibodies, but its role in modulating protective immunity against helminth parasites is unknown. Therefore, we measured levels of Th1-associated IgG2a as well as Th2-associated IgG1 and total IgE antibodies in MGL1 ${ }^{-/-}$ and $\mathrm{MGL1}^{+/+}$mice at different time points following infection with T. crassiceps.

Early in infection, T. crassiceps-infected $\mathrm{MGL1}^{+/+}$and $\mathrm{MGL1}^{-/-}$mice displayed comparable levels of T. crassiceps Ag-specific Th1-associated IgG2a antibodies (data not shown). However, by week 8 after infection, $\mathrm{MGL1}^{+/+}$mice displayed significantly higher titers of specific IgG2a antibodies against T. crassiceps antigens (Figure 5(a)). By contrast, no clear differences were observed in Th2-associated IgG1 production; $\mathrm{MGLI}^{+/+}$mice displayed high titers of anti-T. crassiceps-specific IgG1 that were similar to those in $\mathrm{MGL1}^{-/-}$mice at week 8 after infection (Figure 5(b)). Although Th2-associated IgE has been shown to play a role in mediating immunity against certain helminths, we found that T. crassiceps-infected $\mathrm{MGLl}^{+/+}$mice harbored a lower parasite burden despite producing significantly lower levels of IgE compared to similarly infected $\mathrm{MGL1}^{-/-}$mice, which displayed higher levels of total IgE (Figure 5(c)).

Additionally, we also compared the cytokine production by splenocytes from these mice in response to either $25 \mu \mathrm{g} / \mathrm{mL}$ TcSol or $1 \mu \mathrm{g} / \mathrm{mL}$ plate-bound anti-CD3 antibody. Anti-CD3 (data not shown) or TcSol-stimulated splenocytes from both strains produced similar levels of IFN- $\gamma$ at $2 \mathrm{wk}$ after infection (Figure 6(a)). However, 4 and 8 weeks after infection, the IFN- $\gamma$ production by the spleen cells of $\mathrm{MGL1}^{-/-}$mice decreased and did not reach the level produced by $\mathrm{MGL1}^{+/+}$splenocytes (Figure 6(a)). Similarly, as early as $2 \mathrm{wk}$ after infection, the splenocytes from the $\mathrm{MGL1}^{-/-}$and $\mathrm{MGL1}^{+/+}$mice produced comparable levels of IL-4 (Figure 6(b)). However, by weeks 4 and 8 after infection, $\mathrm{MGL1}^{-/-}$mice produced significantly more IL-4 than the 

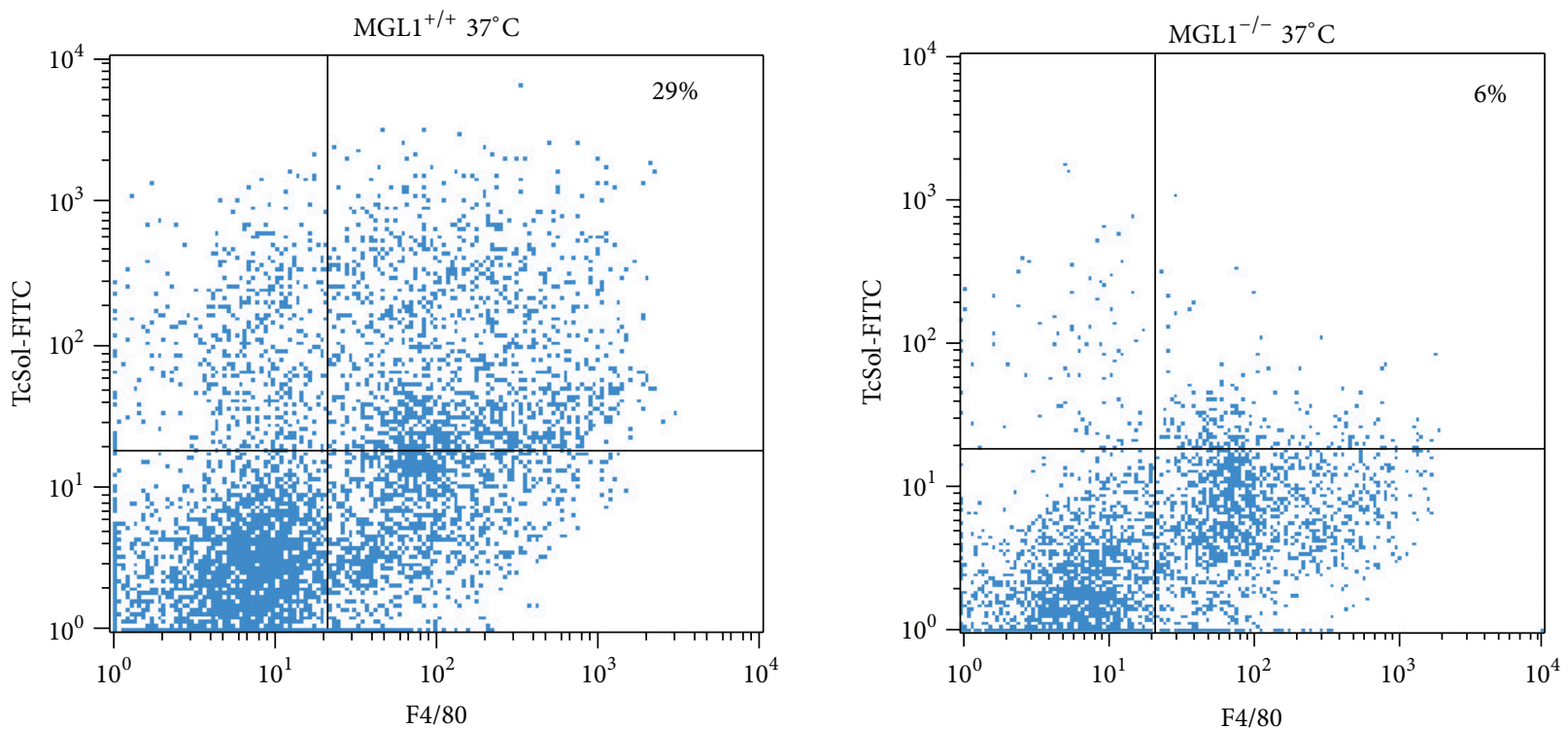

(a)

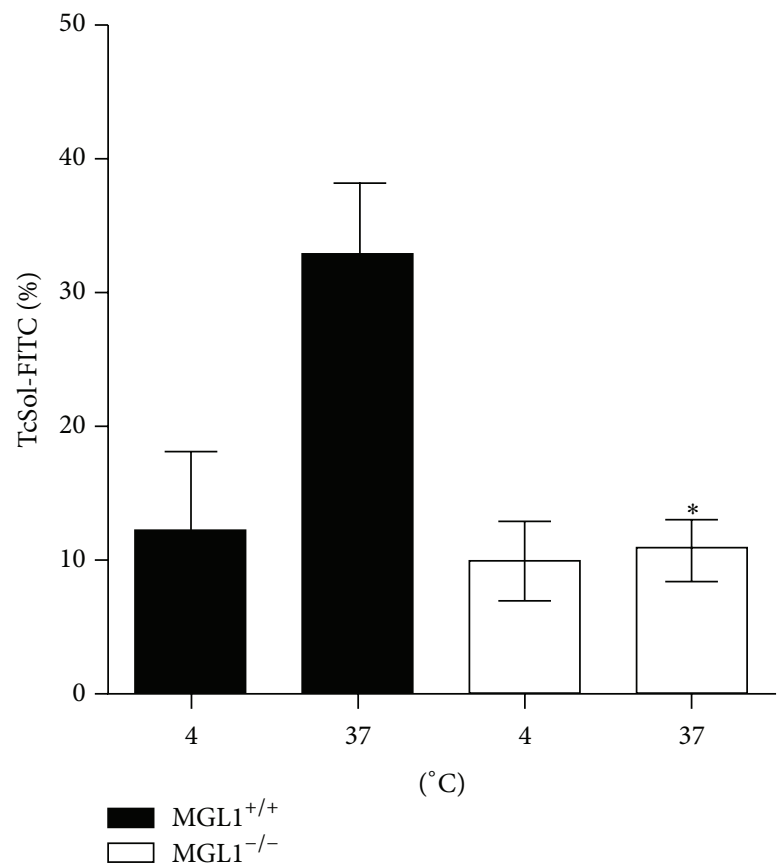

(b)

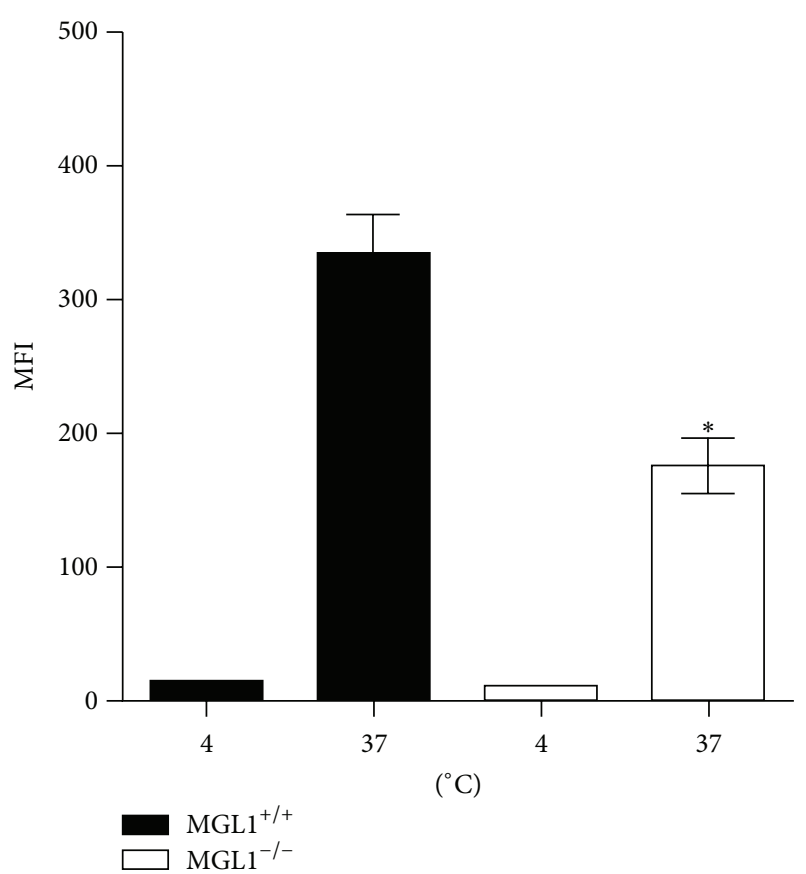

(c)

FIgure 2: Peritoneal M $\phi$ s recognize Taenia crassiceps soluble products through MGL1. M $\phi$ s from naïve MGL1 ${ }^{+/+}$or MGL1 $^{-/-}$mice were incubated with fluorescently labeled TcSol and fluorescence was analyzed by flow cytometry. (a) Representative dot blots indicate $\mathrm{M} \phi$ s from either $\mathrm{MGL1}^{+/+}$or $\mathrm{MGL1}^{-/-}$mice, incubated for 30 minutes with TcSol at $37^{\circ} \mathrm{C}$. (b) Percentage of TcSol-FITC positive naïve peritoneal cells exposed for $30 \mathrm{~min}$. (c) Data are represented as the mean florescence intensity (MFI) of naïve M $\phi$ s exposed to TcES-FITC. Basal levels of autofluorescence were subtracted from all treatments. Data are representative of three independent experiments. ${ }^{*} P<0.05$.

$\mathrm{MGL1}^{+/+}$splenocytes in response to anti-CD3, whereas antigen-specific higher IL-4 production in $\mathrm{MGL1}^{-/-}$splenocytes was only observed at week 4 after infection compared with $\mathrm{MGL1}^{+/+}$cells (Figures 6(b) and 6(c)). Thus, as the infection progressed, splenocytes from $\mathrm{MGLl}^{-/-}$mice produced significantly greater levels of IL- 4 compared with splenocytes from T. crassiceps-infected $\mathrm{MGLI}^{+/+}$mice in response to antiCD3.

3.6. Differential Cytokine Production in $\mathrm{MGLI}^{-1-}$ and $\mathrm{MGLI}^{+/+}$Peritoneal Macrophages. To determine whether $\mathrm{MGLI}^{-/-}$mice had a systemic defect in innate activation, we 


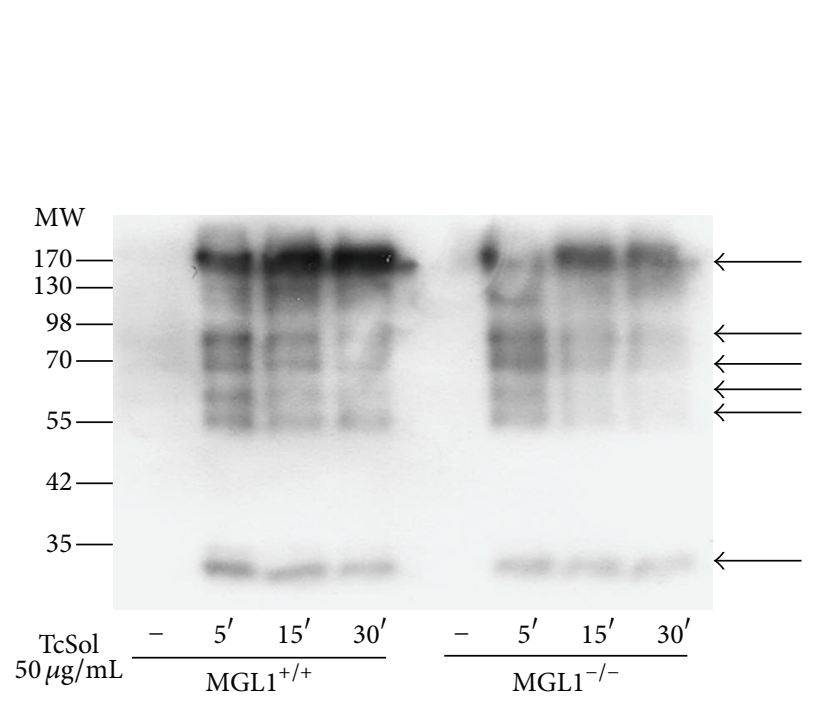

(a)

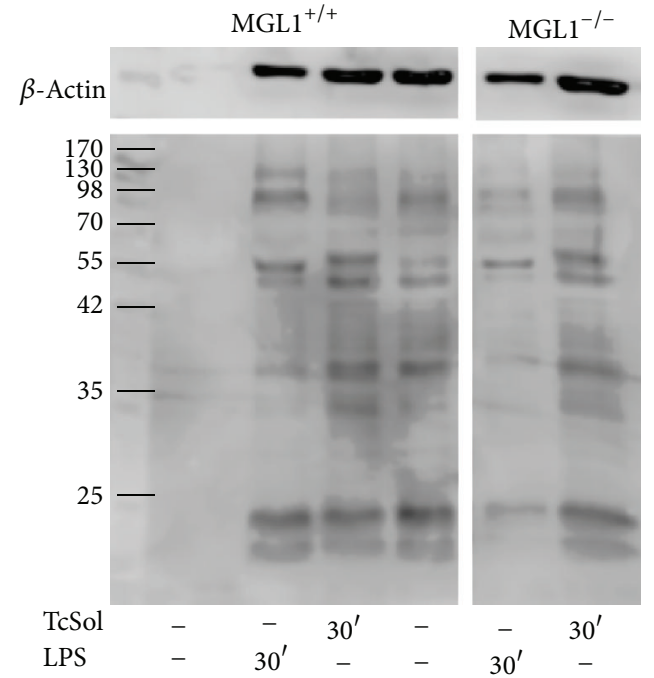

(b)

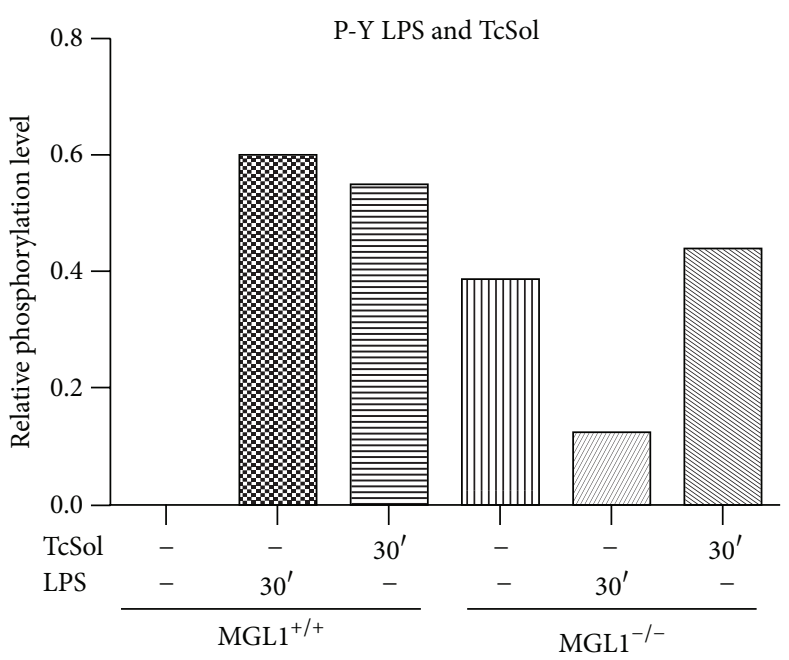

(c)

FIGURE 3: $\mathrm{MGL1}^{-/-}$macrophages display deficient tyrosine phosphorylation in response to TcSol. (a) MGL1 ${ }^{+/+}$and $\mathrm{MGL1}^{-/-}$bone marrowderived $\mathrm{M} \phi$ were synchronized in starvation conditions over night and then were stimulated or not with $\mathrm{TcSol}(50 \mu \mathrm{g} / \mathrm{mL})$ for $5,15 \mathrm{or}$ $30 \mathrm{~min}$. Next, total cell extracts were obtained and resolved by electrophoresis, transferred to nitrocellulose, and probed with monoclonal antiphosphotyrosine antibody. Lane 1, serum-starved $\mathrm{MGLl}^{+/+} \mathrm{M} \phi$ s. Lanes 2-4, serum-starved $\mathrm{MGL1}^{+/+} \mathrm{M} \phi$ s following TcSol exposure for 5, 15 and 30 min, respectively. Lane 5, serum-starved $\mathrm{MGL1}^{-/-} \mathrm{M} \phi$ s. Lanes 6-8, serum-starved MGL1 ${ }^{-/-} \mathrm{M} \phi$ s following TcSol exposure for 5,15 , and $30 \mathrm{~min}$, respectively. Lanes 2-4 show an upregulation of the tyrosine phosphorylation of total proteins, which was sustained for at least $30 \mathrm{~min}$ (arrows). Lanes 6-8 show an unsustained tyrosine phosphorylation of proteins after similar TcSol stimulation of MGL1 ${ }^{-/}$ $\mathrm{M} \phi$ s. (b) Similar experiment using LPS (500 ng/mL) and/or TcSol stimulation for $30 \mathrm{~min}$. (c) Densitometry of western blot placed in (b). Proteins were visualized using a goat anti-mouse secondary conjugated to HRP and a chemiluminescence detection system. Western blots are representative of two independent experiments.

examined the responsiveness of macrophages from $\mathrm{MGL1}^{-/-}$ mice to proinflammatory stimuli. Macrophages were isolated from the peritoneal cavities of both strains of infected mice and either left unstimulated (basal) or stimulated for $24 \mathrm{~h}$ with LPS $(1 \mu \mathrm{g} / \mathrm{mL})$ and IFN- $\gamma(20 \mathrm{ng} / \mathrm{mL})$. The supernatants were collected and analyzed for IL-12, TNF- $\alpha$ and NO production. As shown in Figure 7, macrophages from $\mathrm{MGL1}^{-/-}$mice obtained during the early phase of infection with $T$. crassiceps ( 2 wks) produced lower levels of IL-12 and
TNF- $\alpha$ compared with those from MGL1 ${ }^{+/+}$mice (Figures $7(\mathrm{a})$ and $7(\mathrm{~b}))$. As the infection became chronic, macrophages from infected $\mathrm{MGLI}^{-/-}$mice produced decreased levels of TNF- $\alpha$ (Figure 7(b)), and the NO levels dropped significantly (Figure 7(c)) in both groups, but even more in $\mathrm{MGLl}^{-/-}$ macrophages. These patterns of macrophage response were in contrast to those observed in $\mathrm{MGLI}^{+/+}$macrophages, which showed a better proinflammatory response throughout the infection with higher production of TNF- $\alpha$ and NO in late 


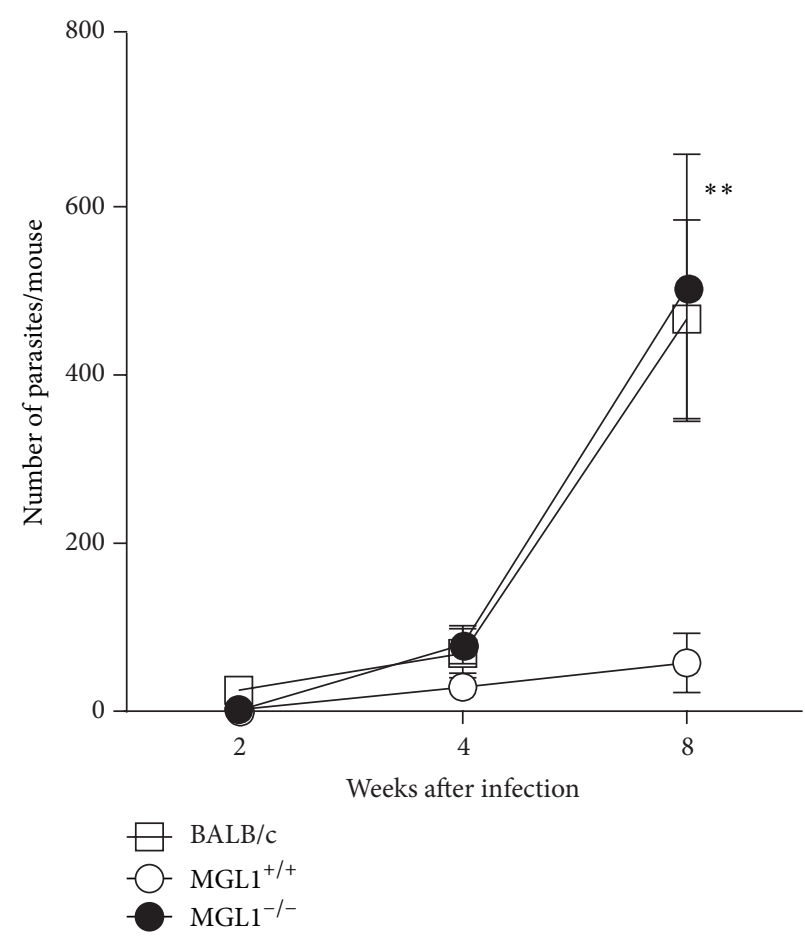

(a)

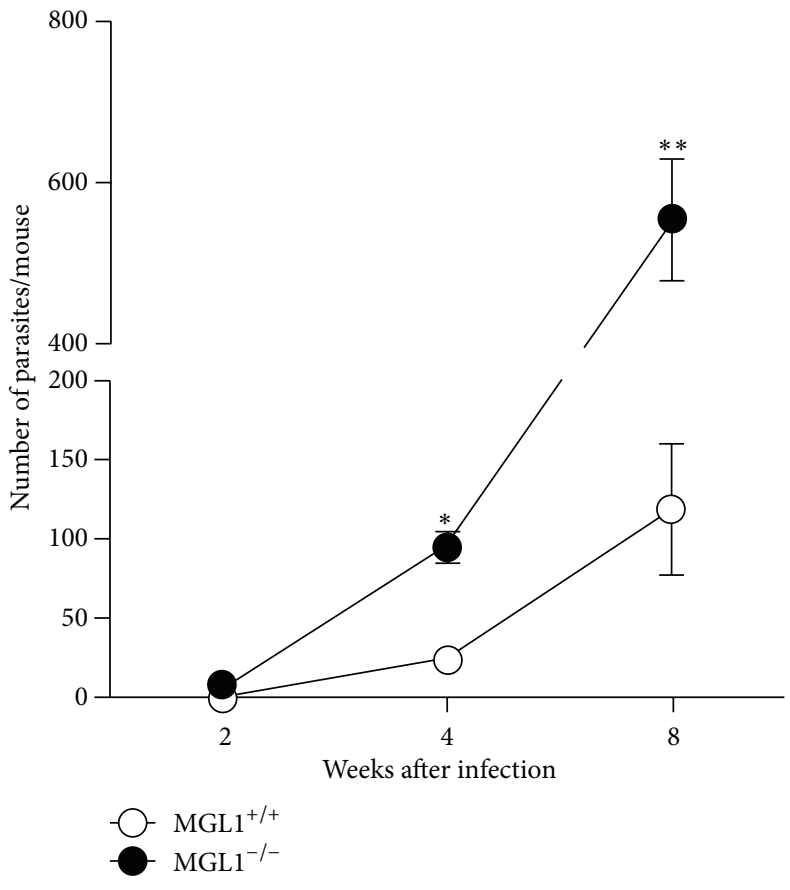

(b)

Figure 4: $\mathrm{MGL1}^{-/-}$mice do not efficiently control T. crassiceps infection. (a) Course of i.p. T. crassiceps infection in MGL1 ${ }^{-/-}$, $\mathrm{MGL1}^{+/+}$and $\mathrm{BALB} / \mathrm{c}$ mice after infection with 20 cysticerci. (b) An independent experiment of the course of i.p. T. crassiceps infection in MGL1 ${ }^{-/-}$and $\mathrm{MGL1}^{+/+}$mice that were similarly infected. Data are expressed as the mean \pm SE of 6 mice per group. ${ }^{*} P<0.01$ comparing MGL1 ${ }^{-/-}$versus $\mathrm{MGLl}^{+/+}$at the same time point.

infections compared to $\mathrm{MGL1}^{-/-}$macrophages (Figures 7(b) and $7(\mathrm{c}))$.

3.7. $\mathrm{MGL1}^{-1-}$ Mice Recruit Alternatively Activated Macrophages. Next, the macrophage polarization genotype was evaluated in adherent peritoneal cells at 4 and 8 weeks after infection. RT-PCR was performed to identify mRNA transcripts of AAM $\phi$ s markers. Infected $\mathrm{MGL1}^{-/-}$mice showed higher expression of arginase-1, Relm- $\alpha$ and Ym-1 than their $\mathrm{MGL1}^{+/+}$counterparts (Figure 8(a)). Moreover, we also analyzed the macrophage surface expression of other markers associated with alternative activation by flow cytometry. Surface expression of the MR, IL- $4 \mathrm{R} \alpha$, and PD-L2 has previously been associated with $\mathrm{AAM} \phi \mathrm{s}$ in distinct helminth infections [31]. Indeed, we found differences between the two strains in the expression of these molecules during $T$. crassiceps infection. Interestingly, during chronic infection (8 weeks), the macrophages from $\mathrm{MGL1}^{-/-}$mice expressed twice as much PD-L2 as macrophages from $\mathrm{MGL1}^{+/+}$mice, which downregulated PD-L2 expression (Figures 8(b) and 8(c)). The MR and IL-4R $\alpha$ expression were also been significantly elevated in macrophages from T. crassiceps-infected MGL1 ${ }^{-/-}$ mice when compared with $\mathrm{MGL1}^{+/+}$mice that expressed lower percentages of both markers (Figures 8(b) and 8(c)).

Given that two related MGL molecules do exist in mice, MGL1 and MGL2, with different carbohydrate specificities, we performed flow cytometry on peritoneal cells for the detection of MGL1 and MGL2 in order to further determine the specific role for MGL1 and not for MGL2 in susceptibility to T. crassiceps. As shown in Figure 8(d), peritoneal macrophages $\left(\mathrm{F} 4 / 80^{+}\right)$from $\mathrm{MGL1}^{+/+}$infected mice did increase MGL1 as well as MGL2 expression after 8 weeks of infection, whereas $\mathrm{MGL1}^{-/-}$macrophages were able to express MGL2 at a similar level than $\mathrm{MGL1}^{+/+}$mice. These data suggest a very fine discrimination between MGL1 and MGL2 to recognize glycan structures on T. crassiceps and its antigens.

\section{Discussion}

The role of CLRs in the recognition of microbial, fungal, and parasitic glycoconjugates has become evident in the last few years [5]. The knowledge in this area has passed from understanding them as "simple endocytic receptors" to important molecules involved in innate immunity with the capacity to trigger intracellular signaling pathways to modify cellular responses to different pathogens [32]. Although the role for CLRs in immunity against fungal and bacterial infections is widely recognized, their role in immunity during helminth infections is much less known [13]. Therefore, in this study, we focused on the role of MGL1 and MGL1mediated signaling in immunity to the cestode T. crassiceps. 


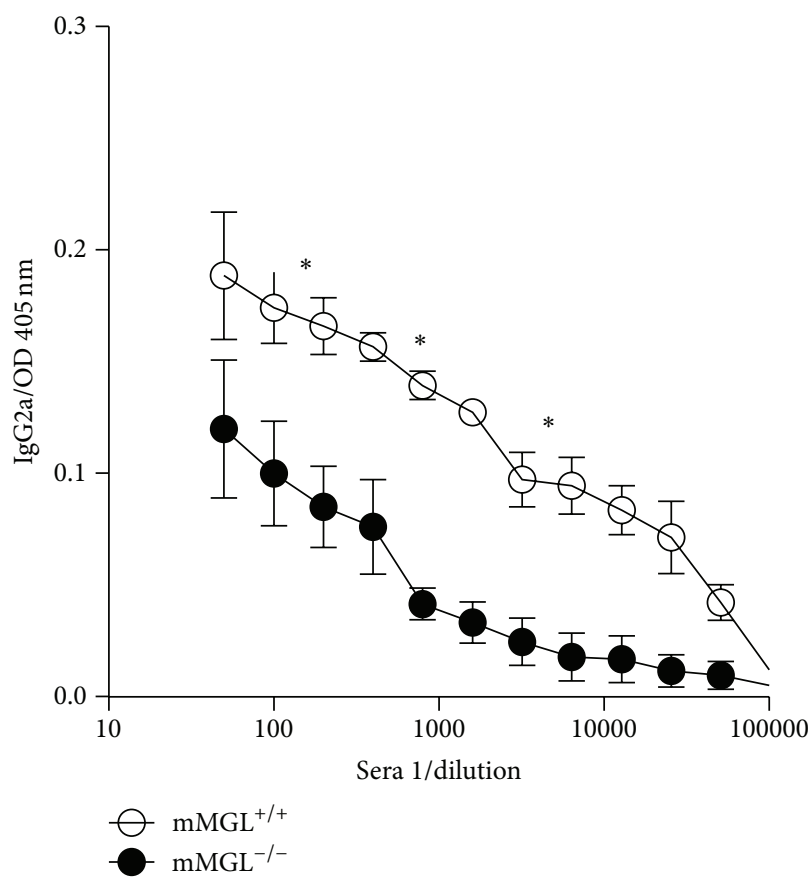

(a)

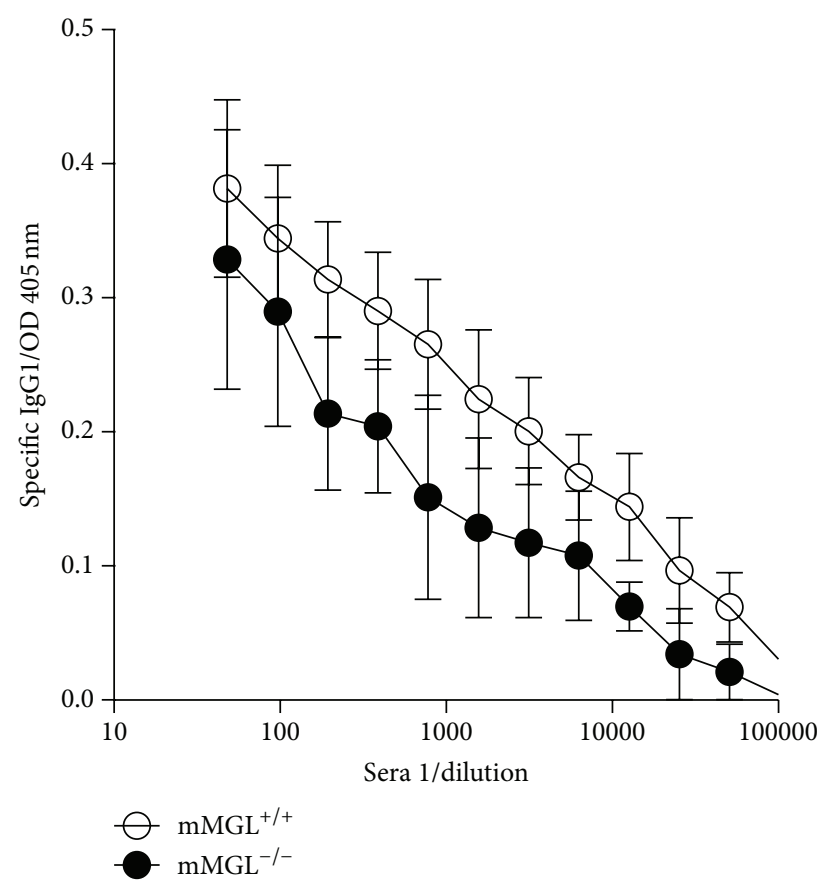

(b)

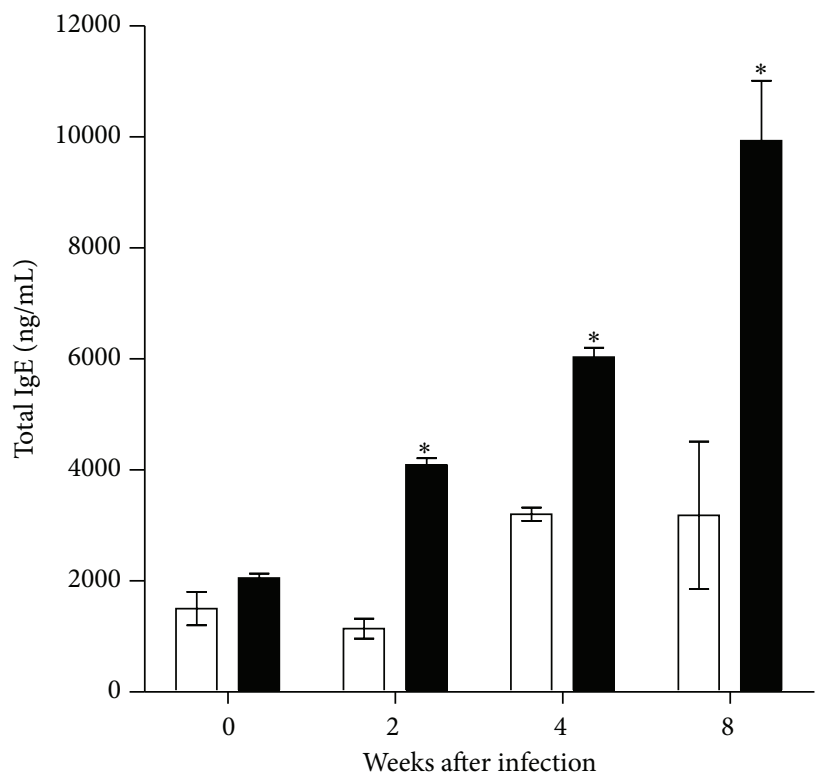

(c)

FIGURE 5: Antibody production during T. crassiceps infection in $\mathrm{MGL1}^{-/-}$and $\mathrm{MGL1}^{+/+}$mice. (a) Anti-T. crassiceps-specific IgG2a; (b) anti-T. crassiceps-specific IgGl; (c) total IgE. Values are the mean \pm SE ( $n=6$ animals) and are representative of three independent experiments. ${ }^{*} \mathrm{P}<0.05$ comparing $\mathrm{MGL1}^{-/-}$versus $\mathrm{MGL1}^{+/+}$mice at the same time point.

It has been previously reported that $T$. crassiceps antigens are rich in structures recognized by concanavalin A. Here, we found that in addition to this and to the previously reported fucose $[17,29]$, glycosylation moieties in T. crassiceps such as galactose and $\mathrm{N}$-acetylgalactosamine are also important. Because the carbohydrates in T. crassiceps antigens, as well as in those of other helminths, are considered important for their modulatory activities [17], we investigated the role of
MGL in the ability to recognize glycosylated structures on TcSol as well as the possible intracellular signaling pathways that they may trigger. The lower recognition of TcSol by $\mathrm{MGL1}^{-1-} \mathrm{M} \phi$ s strongly suggested a role for this C-type lectin in the host-parasite interaction during experimental cysticercosis. Concomitantly, the decreased ability of $\mathrm{MGL1}^{-1-}$ macrophages to bind TcSol was associated with weak phosphotyrosine-mediated intracellular signaling. Therefore, we 


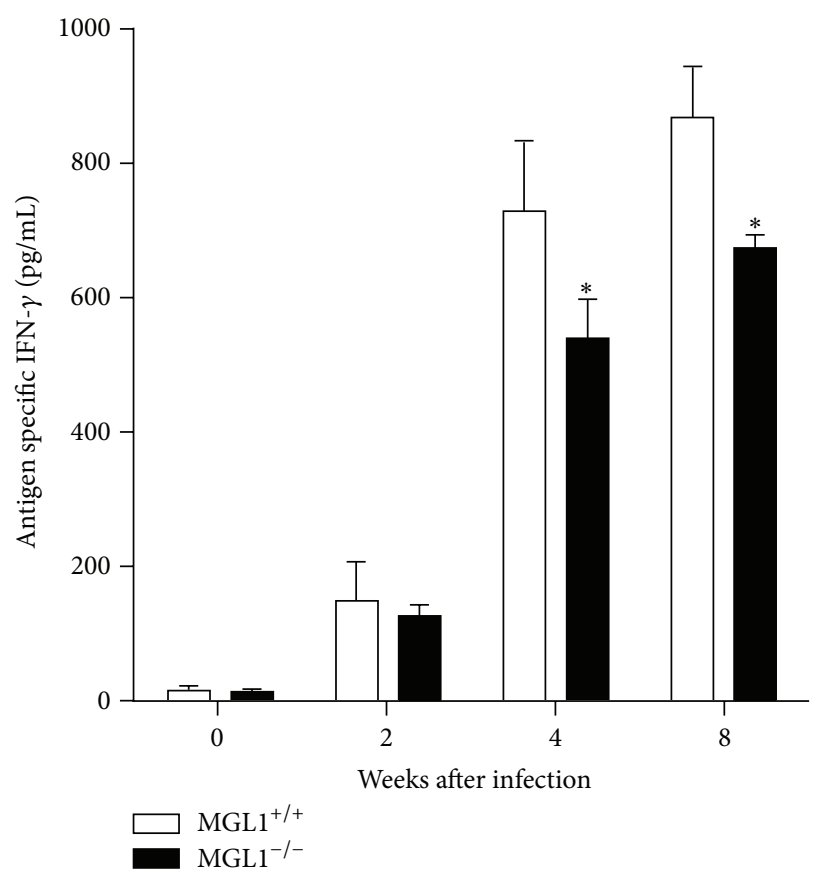

(a)

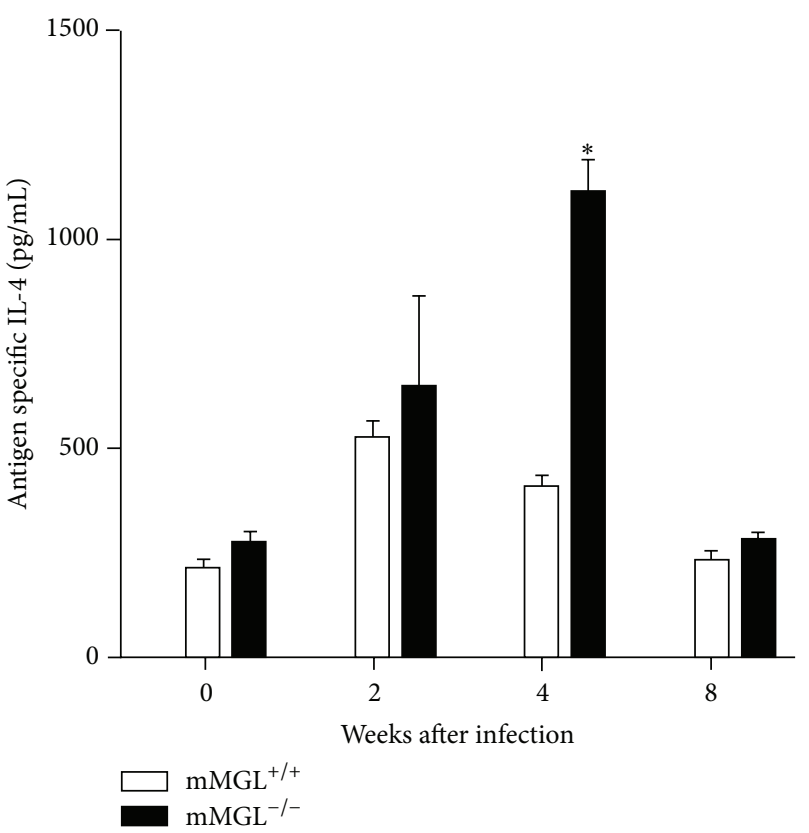

(b)

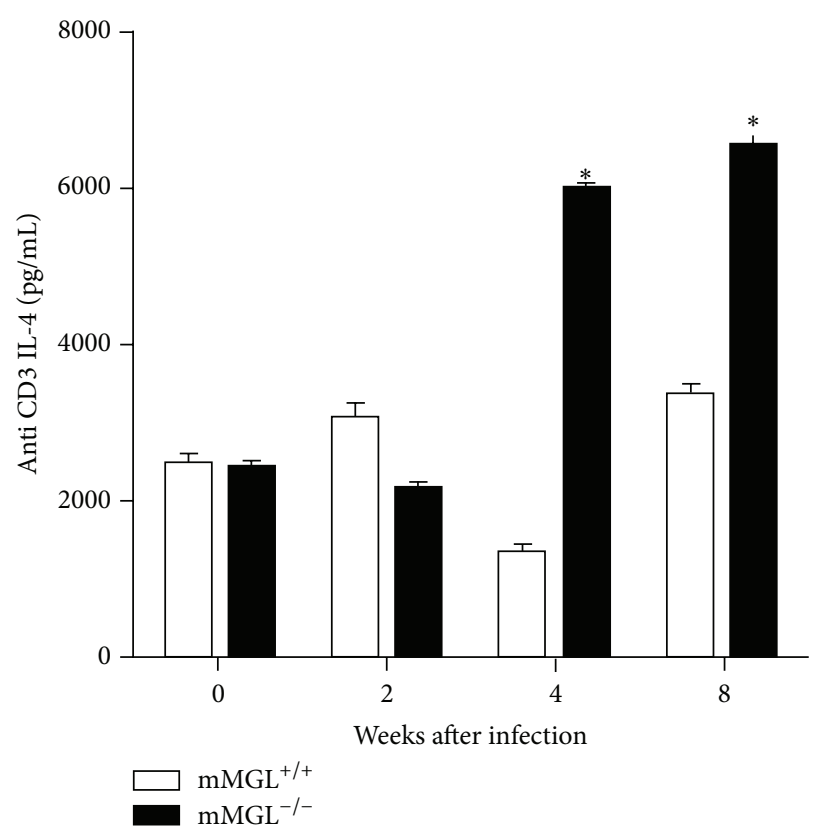

(c)

FIGURE 6: Kinetics of in vitro cytokine production by TcSol-stimulated spleen cells from $\mathrm{MGL1}^{-/-}$and MGL1 ${ }^{+/+}$mice. (a) Antigen-specific IFN- $\gamma$ production, (b) antigen-specific IL-4 production, and (c) polyclonal IL-4 production (anti-CD3) in response to in vitro stimulation with TcSol $(25 \mu \mathrm{g} / \mathrm{mL})$ by splenocytes after $72 \mathrm{~h}$. Data are representative of 2 independent experiments. ${ }^{*} P<0.05$.

performed in vivo assays to determine whether MGL1 recognition of T. crassiceps plays a critical role in the resistance to this helminth infection. Thus, we demonstrate for the first time that mice deficient in the CLR macrophage galactosetype lectin 1 (MGL1) have increased susceptibility to experimental cysticercosis caused by the cestode $T$. crassiceps, with a reduction in the levels of the proinflammatory cytokines
IL-12, IFN- $\gamma$ and TNF- $\alpha$, as well as in NO production. These observations are in line with those reported using anti-MGL antibody engagement on DCs, where MGL-engaged DCs produced higher levels of IL-10 than did DCs treated with the control isotype [20]. In contrast, higher levels of IL-4 and IgE were detected in these mice compared to similarly infected $\mathrm{MGL1}^{+/+}$mice. Although Th2-associated responses and high 


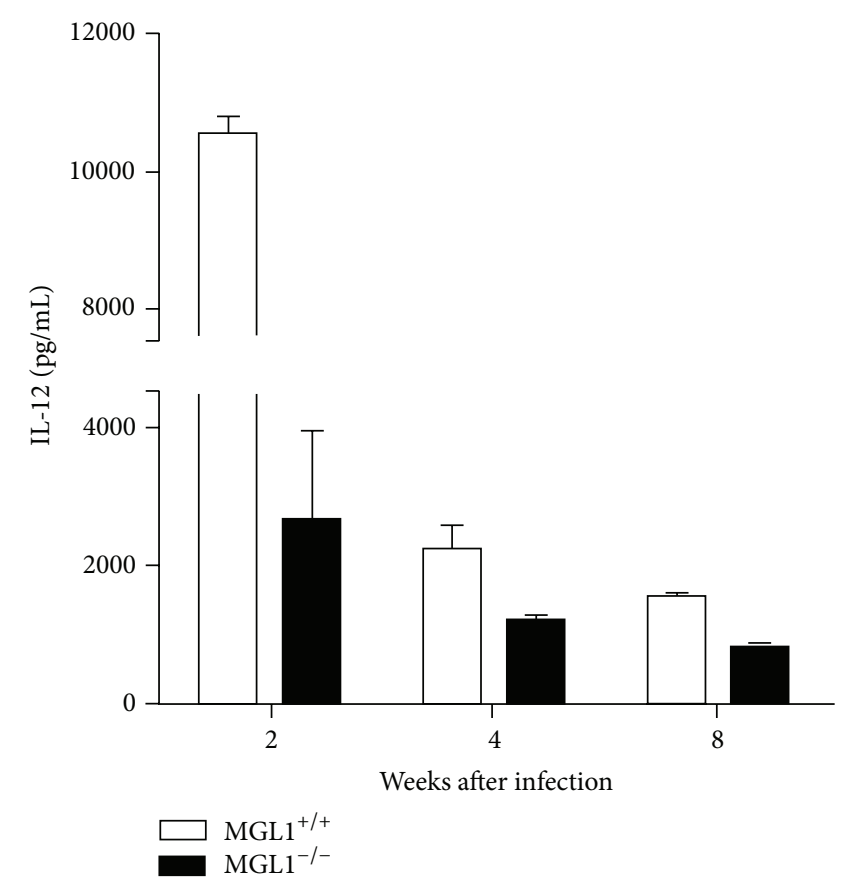

(a)

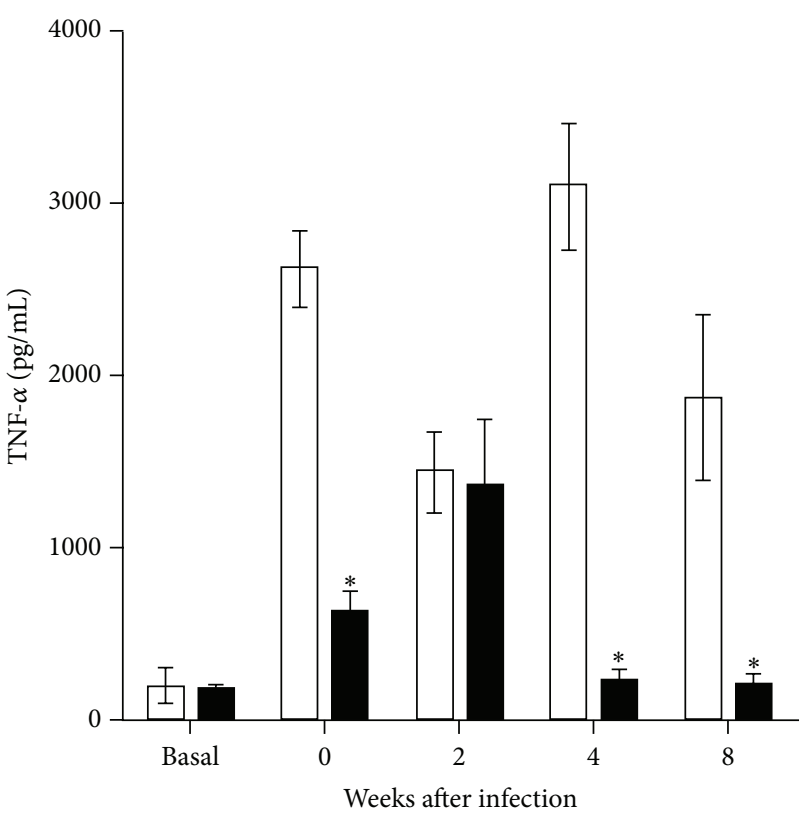

(b)

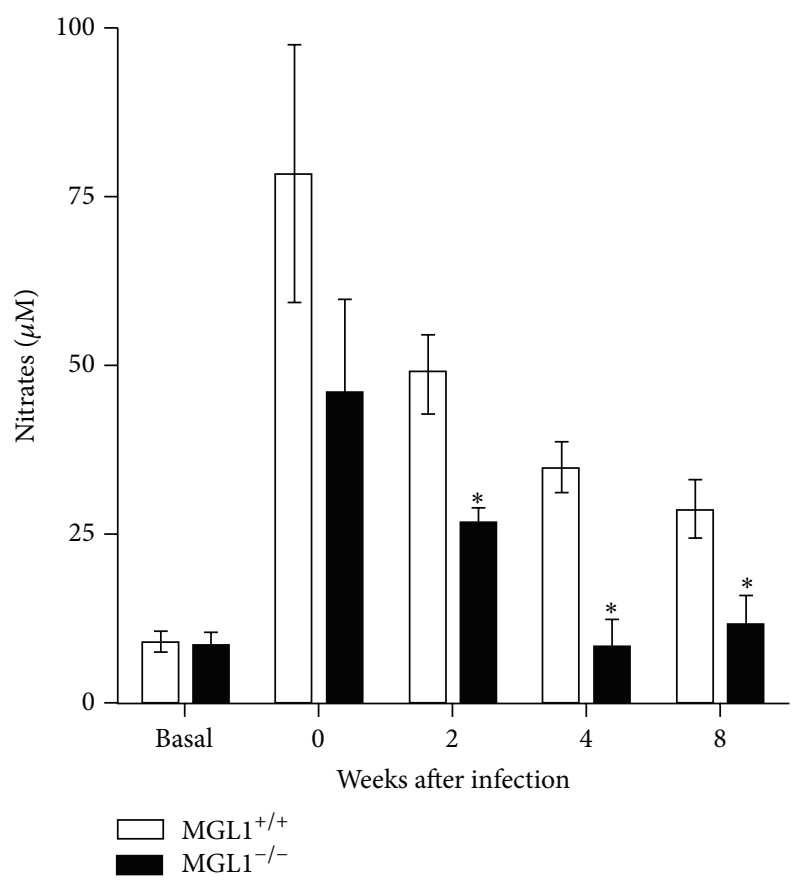

(c)

Figure 7: Peritoneal macrophages from $\mathrm{MGL1}^{-/-}$and $\mathrm{MGL1}^{+/+}$T. crassiceps-infected mice display different responses. Macrophages were obtained at different time points after infection and stimulated with LPS $(1 \mu \mathrm{g} / \mathrm{mL})$ plus IFN- $\gamma(5 \mathrm{ng} / \mathrm{mL})$ for 48 h; supernatants were analyzed for (a) IL-12; (b) TNF- $\alpha$; and (c) NO production. Data are expressed as in Figure $2 .{ }^{*} P<0.05$. Data are representative of 2 independent experiments. ${ }^{*} P<0.05$. 

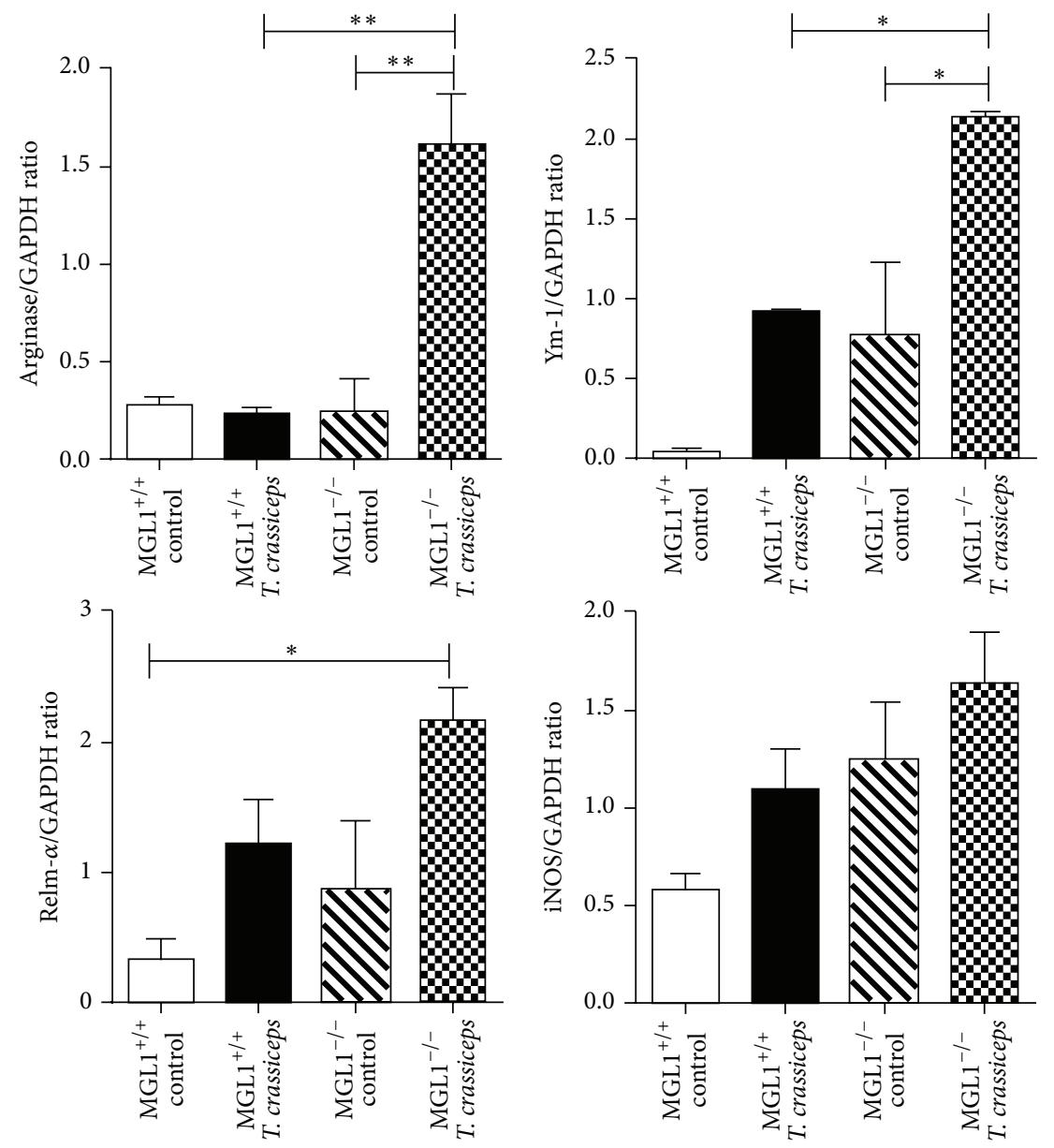

(a)

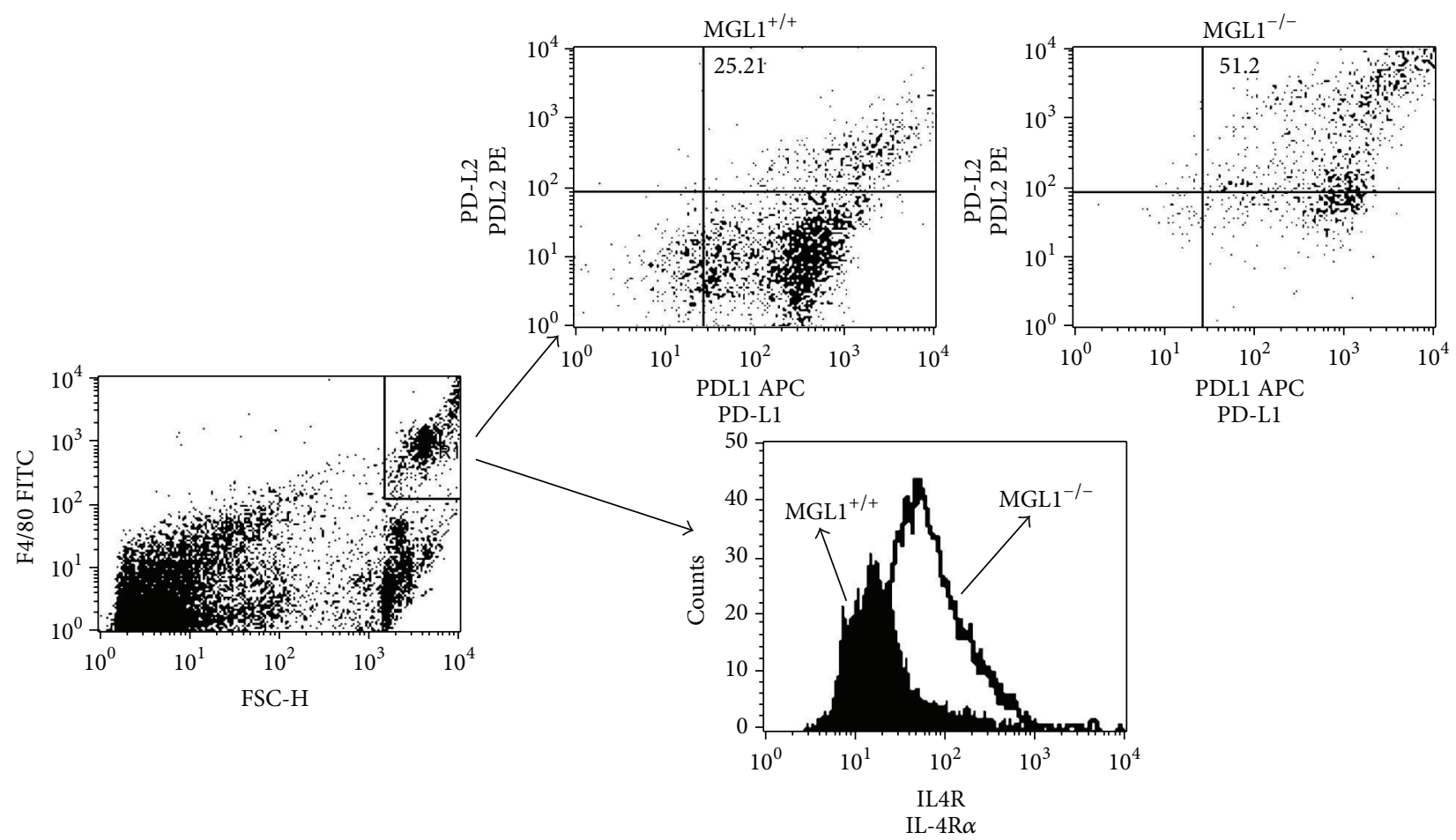

(b)

Figure 8: Continued. 


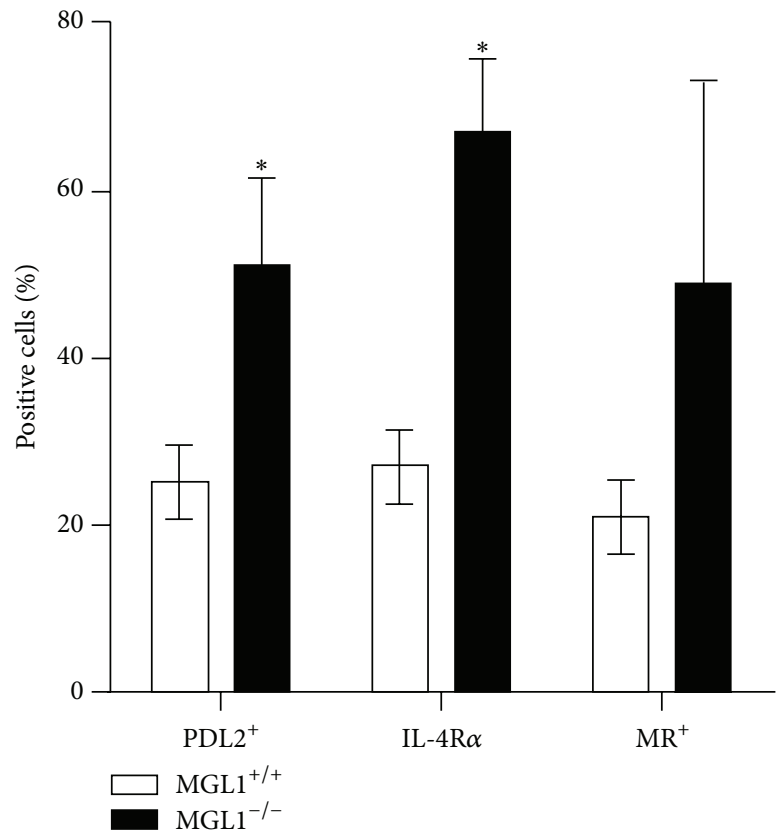

(c)

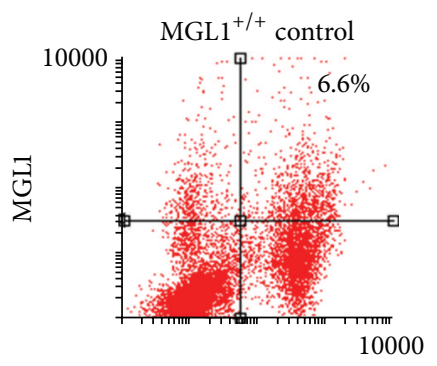

F4/80

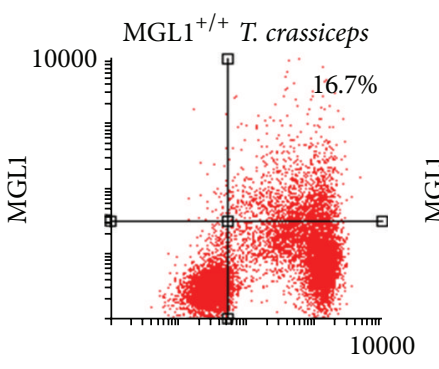

F4/80

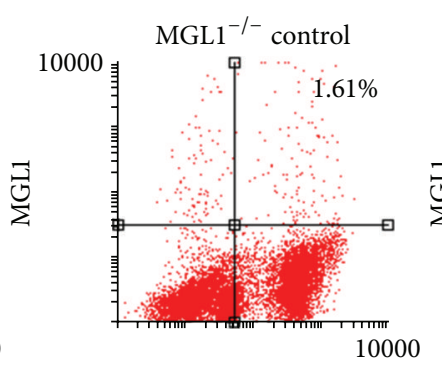

F4/80

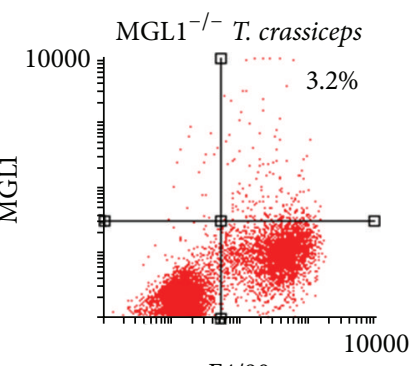

F4/80

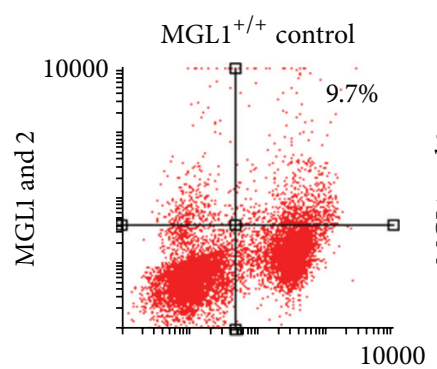

F4/80

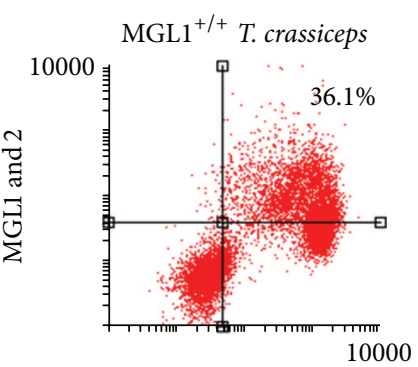

F4/80

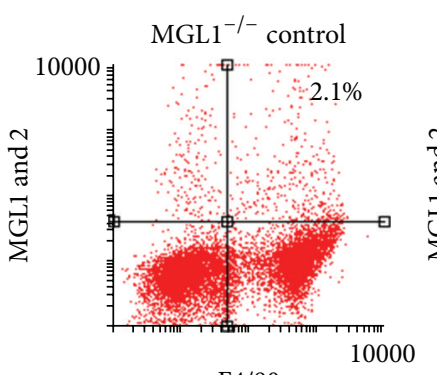

F4/80

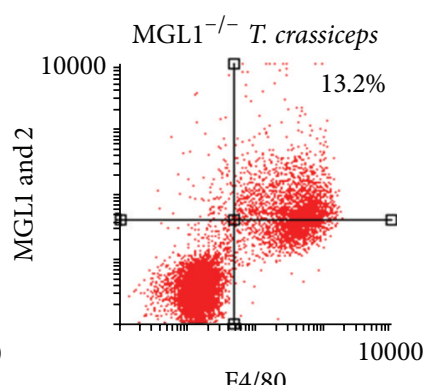

F4/80

(d)

FIGURE 8: $\mathrm{MGL}^{-/-}$mice recruit alternatively activated macrophages. Peritoneal macrophages were obtained from $\mathrm{MGLl}^{-/-}$and MGL1 ${ }^{+/+} \mathrm{T}$. crassiceps-infected mice and processed for RT-PCR or flow cytometry analyses. (a) RT-PCR showing the expression of arginase-1, Ym1, RELM$\alpha$ and iNOS on macrophages obtained at 8 weeks after infection with T. crassiceps. (b) Representative dot plot and histograms demonstrating increased expression of PD-L2, and IL-4R $\alpha$ on $\mathrm{MGL1}^{-/-}$macrophages. (c) Percentages of expression of different surface markers on peritoneal macrophages. (d) Dot plots from PECs showing the expression of MGL1 and MGL2 from uninfected (control) and 8 weeks-infected T. crassiceps $\mathrm{MGLl}^{+/+}$and $\mathrm{MGL1}^{-/-}$mice, numbers on the quadrants indicate average percentage of positive cells. Values are the mean $\pm \mathrm{SE}$

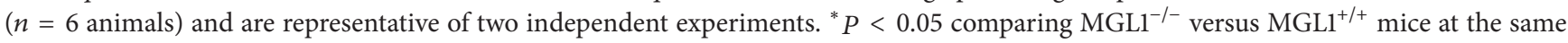
time point. 
levels of $\operatorname{IgE}$ correlate with protection in gastrointestinal helminth infections [33], our data suggest that IgE may have a limited role in mediating protective immunity against T. crassiceps. Notably, despite the greater Th2-associated antibody response in $\mathrm{MGL1}^{-1-}$ mice, these mice displayed greater susceptibility to T. crassiceps. These data agree with those reported by others $[34,35]$ and indicate a new and finely tuned role for MGL1 in activating innate and adaptive immune responses against this parasite. These results also suggest that the MGL1dependent signaling pathway is not only required for inflammatory cytokine production in the early phase of the host response to T. crassiceps infection but also that MGL may play a critical role in the development of Thl-adaptive immunity, both of which may be essential for limiting infection and reducing pathology during experimental cysticercosis.

In vivo, $\mathrm{MGLl}^{-/-}$mice significantly increased recruitment of alternatively activated macrophages, as determined by mRNA transcripts for arginase-1, Ym-1 and FIZZ1, and higher expression of the MR, IL-4R $\alpha$, PD-L2 and MGL2 in their membranes. Thus, a clear alternative activation status in macrophages was observed only in $\mathrm{MGL1}^{-/-}$mice. These findings are in line with previous reports showing alternatively activated macrophages associated with susceptibility in this model [24] and also indicate that MGL1 expression is not necessary for the induction of $\operatorname{AAM} \phi s$ [36]. Together, these data indicate a role for MGL1 in the regulation of inflammation in a model of experimental cysticercosis and suggest that MGL1 may be a critical innate factor in the response to helminths and may be to other parasites.

Although many helminth parasites express a large number of carbohydrates, few CLRs have been associated with helminth recognition and in vivo function; for example, Dectin-2, DC-SIGN, SIGNR3, SIGNR1, and MGL have been shown to recognize several components of S. mansoni [13], but their roles in vivo are unclear. On the other hand, the MR has been associated with uptake of cercariae [12], but no one CLR has been demonstrated to be essential for resistance to such infection. Moreover, in another helminth infection, the absence of the MR during Trichuris muris challenge was irrelevant for either an immune response or resistance to this worm infection [14]. However, $\mathrm{MR}^{-/-}$mice were recently demonstrated to exhibit increased survival to Mesocestoides corti infection, a neurocysticercosis model, mainly through the downregulation of inflammatory responses [37]. These observations highlight the role of different CLRs in addressing distinct helminth infections and also suggest that it is possible to identify differential roles of CLRs depending upon the type of helminth challenge.

The specificity of rodent MGL1 has been addressed in at least two papers $[38,39]$ where was shown MGL1 has a primary specificity for the Lewis X determinant, and it may additionally bind biantennary glycans ending in LacNAc or LacDiNAc. We have previously shown that Tcsol contains glycoconjugates binding ConA, may be $\mathrm{N}$-glycans and the $T$. crassiceps metacestode $\mathrm{N}$-glycans described by Jang Lee et al. [29] include biantennary and triantennary LacNAc-terminated structures that could explain our MGL1 binding observed. Alternatively or complementarily, the Fuc alphal-3 GlcNAc antenna might constitute MGL1 targets, as the motif is related to Lewis X. The fact that MGL2 expression was unaffected by MGL1 deletion, suggest that such targets may be useful to trigger better immunity against this helminth.

Here, we add to the knowledge of the role of CLRs in mediating possible immune activation and resistance in vivo to the helminth T.crassiceps, which may mediate cellular activation via tyrosine phosphorylation. These data agree with those recently reported by Mishra et al. [37], who described a potential role for the MR in inducing proinflammatory responses to the cestode $M$. corti. Thus, it is possible that some CLRs are involved in proinflammatory responses, whereas other CLRs may induce regulatory responses, as has been observed in vitro for different helminth antigen-derived molecules that are rich in carbohydrate residues [40, 41]. In fact, several helminth-derived glycoconjugates have been shown to downregulate the inflammatory response of DCs in response to different TLR ligands [41, 42], and a possible signaling through the c-RAF-dependent pathway has recently been proposed as a modulator of TLR-mediated inflammatory responses [40]. All these data support the idea previously suggested by Teale's group [11], indicating that given the complexity of helminth-derived glycomolecules it may be expected that they play distinct roles, including roles in strong regulatory mechanisms as well as the induction of protective responses, which in turn are likely dependent on the specific CLRs that bind such glycoconjugates.

In summary, in this study, we have demonstrated for the first time that cestode-derived molecules are recognized by MGL1 on M $\phi$ s and that such interaction triggers phosphotyrosine-mediated intracellular signaling, which most likely induces inflammatory responses in $M \phi s$ and affects the immune response as well as possible resistance to T. crassiceps infection.

\section{Conflict of Interests}

The authors declare that there is no conflict of interests regarding the publication of this paper.

\section{Acknowledgments}

This work was supported by grants from Dirección General de Apoyo al Personal Académico-UNAM IN213512, Instituto de Ciencia y Tecnología del Distrito Federal 319/2010 and PINV11-16 (301/2001), and Consejo Nacional de Ciencia y Tecnología 167799. It is part of the requirements to obtain the $\mathrm{PhD}$ degree in the postgraduate program Doctorado en Ciencias Biomédicas, UNAM for Daniel Montero-Barrera, who was supported by a fellowship from CONACYT-Mexico.

\section{References}

[1] S. Akira and K. Takeda, "Toll-like receptor signalling," Nature Reviews Immunology, vol. 4, no. 7, pp. 499-511, 2004.

[2] J. Aliberti, J. G. Valenzuela, V. B. Carruthers et al., "Molecular mimicry of a CCR5 binding-domain in the microbial activation of dendritic cells," Nature Immunology, vol. 4, no. 5, pp. 485490, 2003. 
[3] C. Brodskyn, J. Patricio, R. Oliveira et al., "Glycoinositolphospholipids from Trypanosoma cruzi interfere with macrophages and dendritic cell responses," Infection and Immunity, vol. 70, no. 7, pp. 3736-3743, 2002.

[4] K. V. Vukman, A. Ravidà, A. M. Aldridge, and S. M. O’Neill, "Mannose receptor and macrophage galactose-type lectin are involved in Bordetella pertussis mast cell interaction," Journal of Leukocyte Biology, vol. 94, no. 3, pp. 439-448, 2013.

[5] A. Vázquez-Mendoza, J. C. Carrero, and M. Rodriguez-Sosa, "Parasitic infections: a role for C-type lectins receptors," BioMed Research International, vol. 2013, Article ID 456352, 11 pages, 2013.

[6] G. D. Brown and S. Gordon, "Immune recognition of fungal $\beta$ glucans," Cellular Microbiology, vol. 7, no. 4, pp. 471-479, 2005.

[7] E. P. McGreal, J. L. Miller, and S. Gordon, "Ligand recognition by antigen-presenting cell C-type lectin receptors," Current Opinion in Immunology, vol. 17, no. 1, pp. 18-24, 2005.

[8] R. M. Maizels and M. Yazdanbakhsh, "Immune regulation by helminth parasites: cellular and molecular mechanisms," Nature Reviews Immunology, vol. 3, no. 9, pp. 733-744, 2003.

[9] M. Okano, A. R. Satoskar, K. Nishizaki, M. Abe, and D. A. Harn Jr., "Induction of Th2 responses and IgE is largely due to carbohydrates functioning as adjuvants on Schistosoma mansoni egg antigens," Journal of Immunology, vol. 163, no. 12, pp. 6712-6717, 1999.

[10] S. Tundup, L. Srivastava, and D. A. Harn Jr., "Polarization of host immune responses by helminth-expressed glycans," Annals of the New York Academy of Sciences, vol. 1253, pp. E1-E13, 2012.

[11] J. I. Alvarez, J. Rivera, and J. M. Teale, "Differential release and phagocytosis of tegument glycoconjugates in neurocysticercosis: implications for immune evasion strategies," PLoS Neglected Tropical Diseases, vol. 2, no. 4, article e218, 2008.

[12] R. A. Paveley, S. A. Aynsley, J. D. Turner et al., “The Mannose Receptor (CD206) is an important pattern recognition receptor (PRR) in the detection of the infective stage of the helminth Schistosoma mansoni and modulates IFN $\gamma$ production," International Journal for Parasitology, vol. 41, no. 13-14, pp. 1335-1345, 2011.

[13] N. S. Prasanphanich, M. L. Mickum, J. Heimburg-Molinaro, and R. D. Cummings, "Glycoconjugates in host-helminth interactions," Frontiers in Immunology, vol. 4, article 240, 2013.

[14] M. L. Deschoolmeester, L. Martinez-Pomares, S. Gordon, and K. J. Else, "The mannose receptor binds Trichuris muris excretory/secretory proteins but is not essential for protective immunity," Immunology, vol. 126, no. 2, pp. 246-255, 2009.

[15] L. Gómez-García, I. Rivera-Montoya, M. Rodríguez-Sosa, and L. I. Terrazas, "Carbohydrate components of Taenia crassiceps metacestodes display Th2-adjuvant and anti-inflammatory properties when co-injected with bystander antigen," Parasitology Research, vol. 99, no. 4, pp. 440-448, 2006.

[16] J. K. Nono, K. Pletinckx, M. B. Lutz, and K. Brehm, "Excretory/ secretory-products of echinococcus multilocularis larvae induce apoptosis and tolerogenic properties in dendritic cells in vitro," PLoS Neglected Tropical Diseases, vol. 6, no. 2, Article ID e1516, 2012.

[17] C. A. Terrazas, L. Gómez-García, and L. I. Terrazas, "Impaired pro-inflammatory cytokine production and increased Th2biasing ability of dendritic cells exposed to Taenia excreted/ secreted antigens: a critical role for carbohydrates but not for STAT6 signaling," International Journal for Parasitology, vol. 40, no. 9, pp. 1051-1062, 2010.
[18] L. I. Terrazas, F. Sánchez-Muñoz, M. Pérez-Miranda et al., "Helminth excreted/secreted antigens repress expression of LPS-induced let-7i but not mir-146a and mir-155 in human dendritic cells," BioMed Research International, vol. 2013, Article ID 972506, 6 pages, 2013.

[19] L. Gómez-García, L. M. López-Marín, R. Saavedra, J. L. Reyes, M. Rodríguez-Sosa, and L. I. Terrazas, "Intact glycans from cestode antigens are involved in innate activation of myeloid suppressor cells," Parasite Immunology, vol. 27, no. 10-11, pp. 395-405, 2005.

[20] C. Napoletano, I. G. Zizzari, A. Rughetti et al., "Targeting of macrophage galactose-type C-type lectin (MGL) induces DC signaling and activation," European Journal of Immunology, vol. 42, no. 4, pp. 936-945, 2012.

[21] H. Towbin, T. Staehelin, and J. Gordon, "Electrophoretic transfer of proteins from polyacrylamide gels to nitrocellulose sheets: procedure and some applications," Proceedings of the National Academy of Sciences of the United States of America, vol. 76, no. 9, pp. 4350-4354, 1979.

[22] M. B. Lutz, N. Kukutsch, A. L. J. Ogilvie et al., "An advanced culture method for generating large quantities of highly pure dendritic cells from mouse bone marrow," Journal of Immunological Methods, vol. 223, no. 1, pp. 77-92, 1999.

[23] P. Migliorini, G. Corradin, and S. B. Corradin, "Macrophage $\mathrm{NO}_{2}^{-}$production as a sensitive and rapid assay for the quantitation of murine IFN- $\gamma$," Journal of Immunological Methods, vol. 139, no. 1, pp. 107-114, 1991.

[24] J. L. Reyes, C. A. Terrazas, J. Alonso-Trujillo, N. van Rooijen, A. R. Satoskar, and L. I. Terrazas, "Early removal of alternatively activated macrophages leads to Taenia crassiceps cysticercosis clearance in vivo," International Journal for Parasitology, vol. 40, no. 6, pp. 731-742, 2010.

[25] S. Jitrapakdee, M. St Maurice, I. Rayment, W. W. Cleland, J. C. Wallace, and P. V. Attwood, "Structure, mechanism and regulation of pyruvate carboxylase," The Biochemical Journal, vol. 413, no. 3, pp. 369-387, 2008.

[26] L. K. Fritz-Laylin, S. E. Prochnik, M. L. Ginger et al., "The genome of Naegleria gruberi illuminates early eukaryotic versatility," Cell, vol. 140, no. 5, pp. 631-642, 2010.

[27] E. van Liempt, S. J. van Vliet, A. Engering et al., "Schistosoma mansoni soluble egg antigens are internalized by human dendritic cells through multiple C-type lectins and suppress TLRinduced dendritic cell activation," Molecular Immunology, vol. 44, no. 10, pp. 2605-2615, 2007.

[28] L. Guasconi, M. C. Serradell, A. P. Garro, L. Iacobelli, and D. T. Masih, "C-type lectins on macrophages participate in the immunomodulatory response to Fasciola hepatica products," Immunology, vol. 133, no. 3, pp. 386-396, 2011.

[29] J. Jang Lee, S. Dissanayake, M. Panico, H. R. Morris, A. Dell, and S. M. Haslam, "Mass spectrometric characterisation of Taenia crassicepsmetacestode N-glycans," Molecular and Biochemical Parasitology, vol. 143, no. 2, pp. 245-249, 2005.

[30] J. L. Reyes, C. A. Terrazas, L. Vera-Arias, and L. I. Terrazas, "Differential response of antigen presenting cells from susceptible and resistant strains of mice to Taenia crassiceps infection," Infection, Genetics and Evolution, vol. 9, no. 6, pp. 1115-1127, 2009.

[31] L. I. Terrazas, D. Montero, C. A. Terrazas, J. L. Reyes, and M. Rodríguez-Sosa, "Role of the programmed Death-1 pathway in the suppressive activity of alternatively activated macrophages in experimental cysticercosis," International Journal for Parasitology, vol. 35, no. 13, pp. 1349-1358, 2005. 
[32] J. C. Hoving, G. J. Wilson, and G. D. Brown, "Signalling C-type lectin receptors, microbial recognition and immunity," Cellular Microbiology, vol. 16, no. 2, pp. 185-194, 2014.

[33] J. E. Allen and R. M. Maizels, "Diversity and dialogue in immunity to helminths," Nature Reviews Immunology, vol. 11, no. 6, pp. 375-388, 2011.

[34] L. I. Terrazas, A. R. Satoskar, M. Rodriguez-Sosa, and J. Morales-Montor, "Immunology and cell biology of parasitic diseases 2013," BioMed Research International, vol. 2013, Article ID 101268, 4 pages, 2013.

[35] A. N. Peón, A. Espinoza-Jiménez, and L. I. Terrazas, "Immunoregulation by taenia crassiceps and its antigens," BioMed Research International, vol. 2013, Article ID 498583, 13 pages, 2013.

[36] G. Raes, L. Brys, B. K. Dahal et al., "Macrophage galactosetype C-type lectins as novel markers for alternatively activated macrophages elicited by parasitic infections and allergic airway inflammation," Journal of Leukocyte Biology, vol. 77, no. 3, pp. 321-327, 2005.

[37] P. K. Mishra, E. G. Morris, J. A. Garcia, A. E. Cardona, and J. M. Tealea, "Increased accumulation of regulatory granulocytic myeloid cells in mannose receptor $\mathrm{C}$ type 1-deficient mice correlates with protection in a mouse model of neurocysticercosis," Infection and Immunity, vol. 81, no. 4, pp. 1052-1063, 2013.

[38] M. Tsuiji, M. Fujimori, Y. Ohashi et al., "Molecular cloning and characterization of a novel mouse macrophage C-type lectin, mMGL2, which has a distinct carbohydrate specificity from mMGL1," The Journal of Biological Chemistry, vol. 277, no. 32, pp. 28892-28901, 2002.

[39] P. J. Coombs, M. E. Taylor, and K. Drickamer, “Two categories of mammalian galactose-binding receptors distinguished by glycan array profiling," Glycobiology, vol. 16, no. 8, pp. 1C-7C, 2006.

[40] C. A. Terrazas, M. Alcántara-Hernández, L. Bonifaz, L. I. Terrazas, and A. R. Satoskar, "Helminth-excreted/secreted products are recognized by multiple receptors on DCs to block the TLR response and bias Th2 polarization in a cRAF dependent pathway," The FASEB Journal, vol. 27, no. 11, pp. 4547-4560, 2013.

[41] E. J. Klaver, L. M. Kuijk, L. C. Laan et al., "Trichuris suisinduced modulation of human dendritic cell function is glycanmediated," International Journal for Parasitology, vol. 43, no. 3-4, pp. 191-200, 2013.

[42] P. G. Thomas, M. R. Carter, O. Atochina et al., "Maturation of dendritic cell 2 phenotype by a helminth glycan uses a Toll-like receptor 4-dependent mechanism," The Journal of Immunology, vol. 171, no. 11, pp. 5837-5841, 2003. 

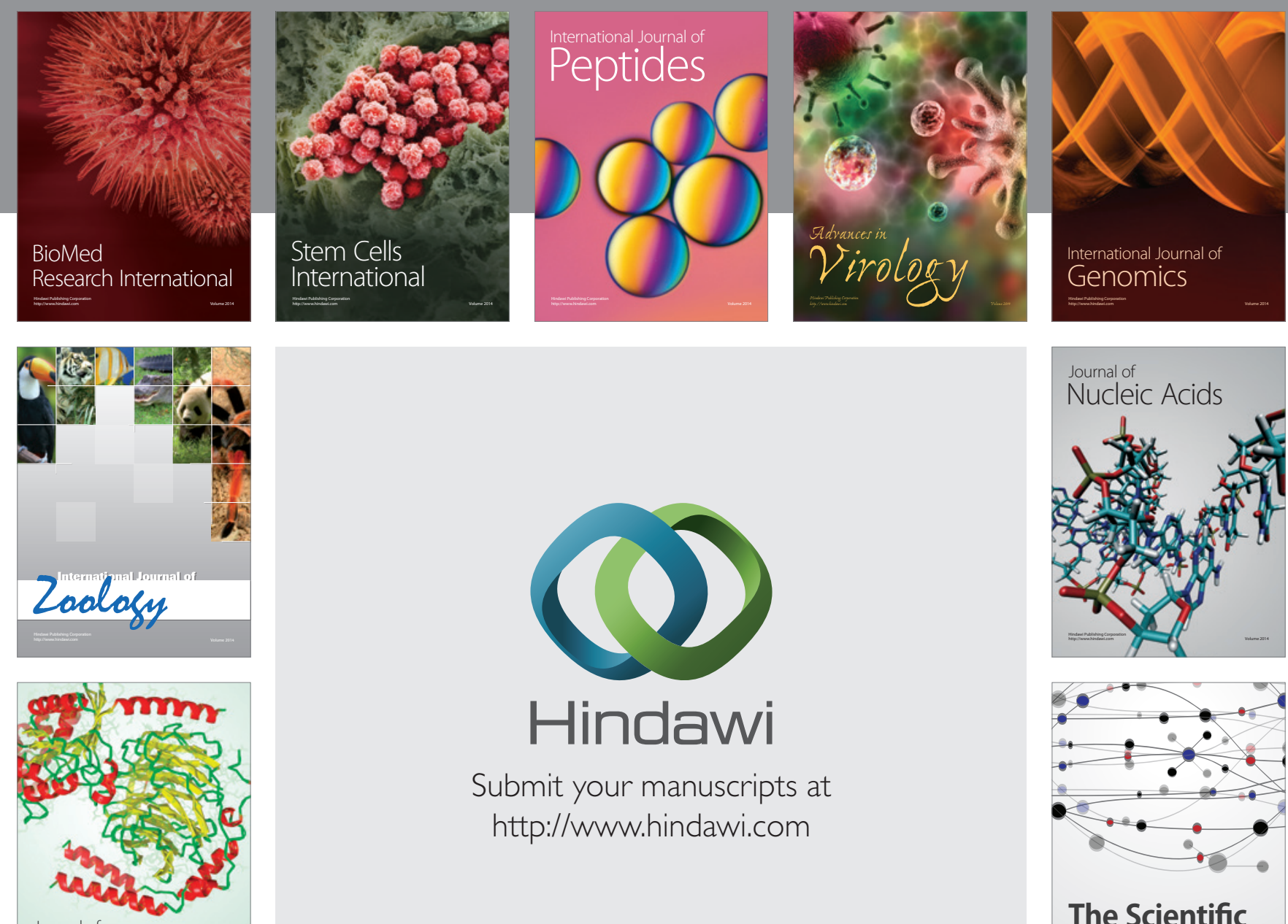

Submit your manuscripts at

http://www.hindawi.com

Journal of
Signal Transduction
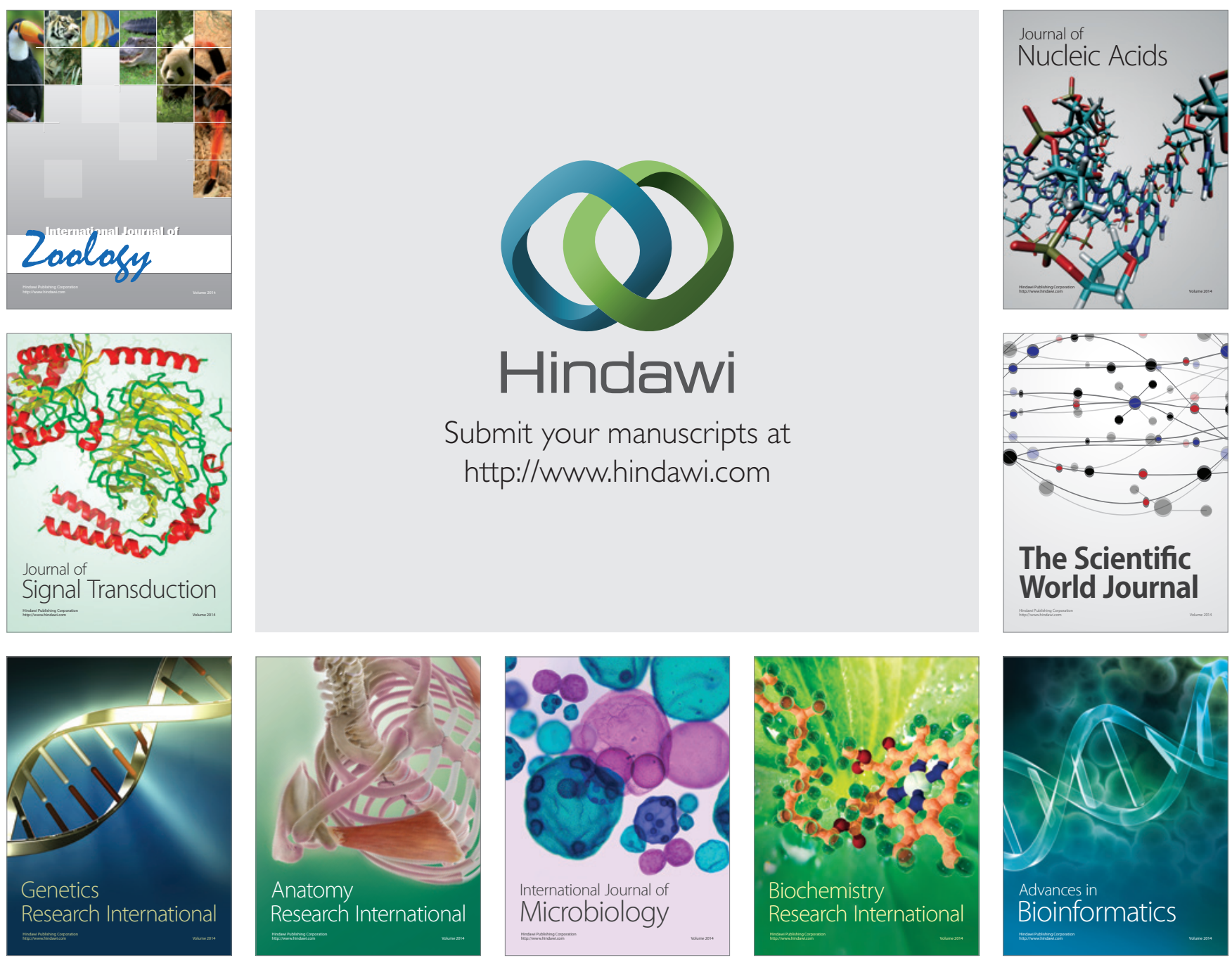

The Scientific World Journal
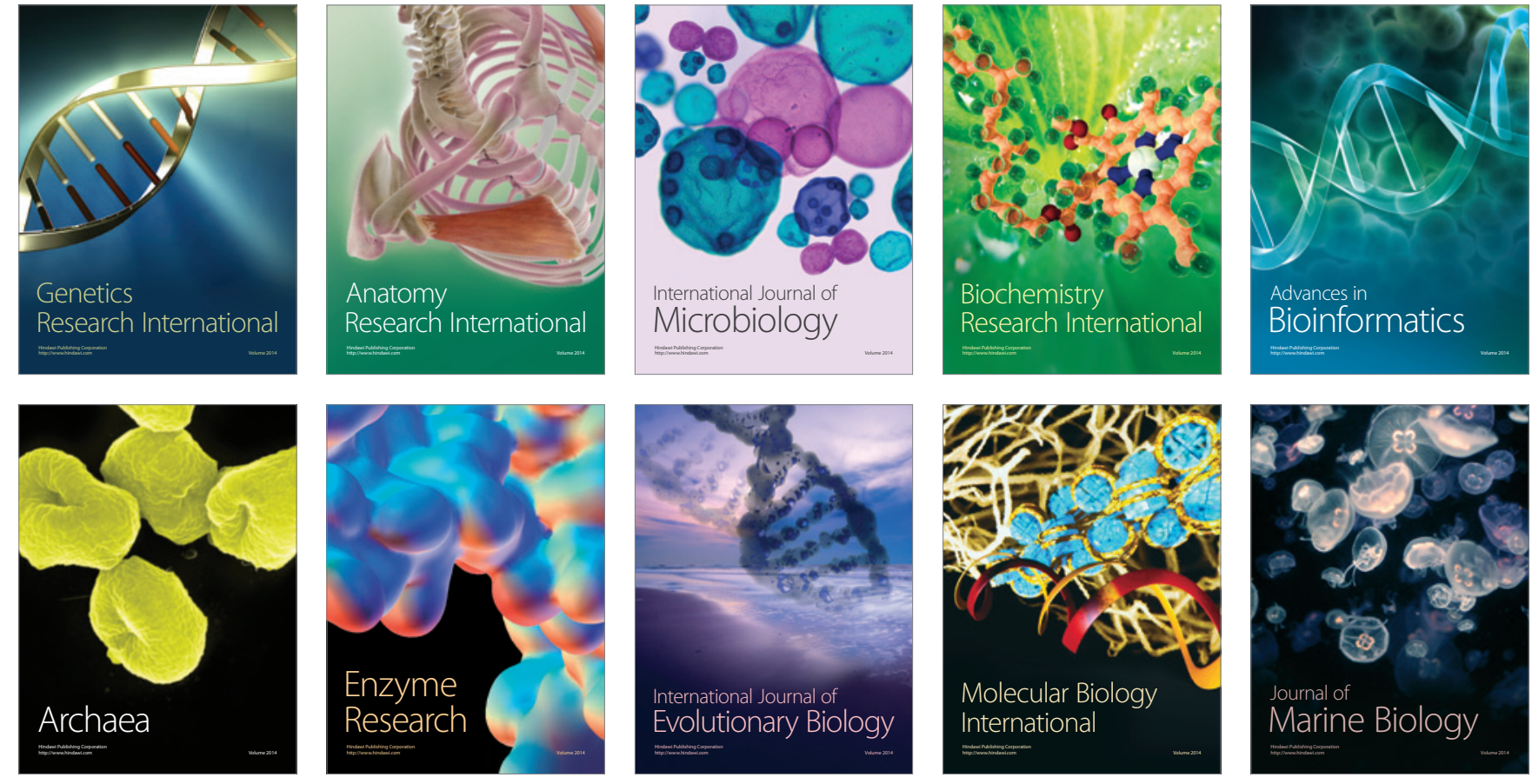